\title{
A Modified Framework for Quantifying Land-Atmosphere Covariability during Hydrometeorological and Soil Wetness Extremes in Oklahoma
}

\author{
RYANN A. WAKEFIELD, ${ }^{\mathrm{a}}$ JEFFrEy B. BASARA,,${ }^{\mathrm{a}, \mathrm{b}}$ JASON C. FurTADO, ${ }^{\mathrm{a}, \mathrm{c}}$ BRADLEy G. Illston, ${ }^{\mathrm{d}}$ \\ Craig. R. Ferguson, ${ }^{\text {eff }}$ AND PETRA M. KLEIN ${ }^{\mathrm{a}}$ \\ ${ }^{\text {a }}$ School of Meteorology, University of Oklahoma, Norman, Oklahoma \\ ${ }^{\mathrm{b}}$ School of Civil Engineering and Environmental Science, University of Oklahoma, Norman, Oklahoma \\ ${ }^{\mathrm{c}}$ South Central Climate Adaptation Science Center, Norman, Oklahoma \\ ${ }^{\mathrm{d}}$ Oklahoma Climatological Survey, University of Oklahoma, Norman, Oklahoma \\ e Atmospheric Sciences Research Center, University at Albany, State University of New York, Albany, New York \\ ${ }^{\mathrm{f}}$ Department of Atmospheric and Environmental Sciences, University at Albany, State University of New York, Albany, New York
}

(Manuscript received 7 September 2018, in final form 12 April 2019)

\begin{abstract}
Global "hot spots" for land-atmosphere coupling have been identified through various modeling studiesboth local and global in scope. One hot spot that is common to many of these analyses is the U.S. southern Great Plains (SGP). In this study, we perform a mesoscale analysis, enabled by the Oklahoma Mesonet, that bridges the spatial and temporal gaps between preceding local and global analyses of coupling. We focus primarily on east-west variations in seasonal coupling in the context of interannual variability over the period spanning 2000-15. Using North American Regional Reanalysis (NARR)-derived standardized anomalies of convective triggering potential (CTP) and the low-level humidity index (HI), we investigate changes in the covariance of soil moisture and the atmospheric low-level thermodynamic profile during seasonal hydrometeorological extremes. Daily CTP and HI $z$ scores, dependent upon climatology at individual NARR grid points, were computed and compared to in situ soil moisture observations at the nearest mesonet station to provide nearly collocated annual composites over dry and wet soils. Extreme dry and wet year CTP and HI $z$-score distributions are shown to deviate significantly from climatology and therefore may constitute atmospheric precursors to extreme events. The most extreme rainfall years differ from climatology but also from one another, indicating variability in the strength of land-atmosphere coupling during these years. Overall, the covariance between soil moisture and CTP/HI is much greater during drought years, and coupling appears more consistent. For example, propagation of drought during 2011 occurred under antecedent CTP and HI conditions that were identified by this study as being conducive to positive dry feedbacks demonstrating potential utility of this framework in forecasting regional drought propagation.
\end{abstract}

\section{Introduction}

Land-atmosphere coupling quantifies the complex interactions between land surface conditions and the atmosphere to better understand the hydrologic cycle and can be viewed from the perspective of the terrestrial and atmospheric segments along with the mutual interactions between the two. Soil moisture plays an important role in the terrestrial segment through surface flux partitioning (Basara and Crawford 2002) and changes in evapotranspiration rates (Teuling et al. 2006; $\mathrm{McPherson}$ et al. 2007). However, these relationships are

Corresponding author: Ryann A. Wakefield, ryann.wakefield@ ou.edu not necessarily linear, and the soil moisture-evaporation relationship may be enhanced as soils become drier (Phillips and Klein 2014; Williams et al. 2016).

Within the atmospheric segment, surface fluxes impact boundary layer development (Rabin et al. 1990; Santanello et al. 2009, 2011, 2013). In addition, near-surface atmospheric moisture can be driven by both nonlocal and local soil moisture anomalies (Atlas et al. 1993; Hong and Kalnay 2000; Pal and Eltahir 2003; Su and Dickinson 2017) and can modify the local environment making it more (or less) favorable for convective precipitation (Pielke 2001).

The scale dependency of these interactions is evident via past studies that have explored coupling through point-scale analyses of diurnal boundary layer development and at the global spatial scale focused within 
the seasonal to interannual time scale. Land surface conditions may reinforce seasonal extremes over a large region (Trenberth and Guillemot 1996; Fischer et al. 2007a,b) and may even play a role in large-scale dynamics (Namias et al. 1988). From the climatological perspective, some regions show a greater atmospheric response to soil moisture anomalies. The first phase of the Global Land-Atmosphere Coupling Experiment (GLACE) found that local land-atmosphere coupling tends to be favored over semiarid/transition regions across climate models (Koster et al. 2004). While coupling strength identified by each individual climate model varied significantly, subsequent studies similarly found stronger coupling in transition regions between arid and humid climates, such as the southern Great Plains (Guo et al. 2006; Koster et al. 2006; Dirmeyer 2006). Transition climates show an increased sensitivity of evapotranspiration (ET) to changes in soil moisture and atmospheric demand, which tends to be more variable (Trenberth 1999; Guo et al. 2006; Koster et al. 2011; Dirmeyer 2011; Wei et al. 2016). Within regions of strong coupling, the strength of soil moisture-evapotranspiration-precipitation relationships has been shown to change in both time and space (Findell and Eltahir 2003b; Guo and Dirmeyer 2013; Basara and Christian 2018). Further, climatologically dry (wet) regions may experience an increase in sensitivity to land surface conditions during (wet) dry months (Schubert et al. 2004; Wei and Dirmeyer 2012). Nonlocal landatmosphere feedbacks have been shown to impact local precipitation, particularly when anomalously dry soils result in suppressed precipitation downstream (Koster et al. 2016).

While several studies have identified regions in which the atmosphere is more sensitive to changes in soil moisture, the sign of these feedbacks is largely dependent upon both the temporal and spatial resolution used to examine these feedbacks (Hohenegger et al. 2009; Meng and Quiring 2010). In addition to local soil moisture extremes, regional gradients have also been argued to serve as a focus for differential diabatic heating and enhanced surface convergence that may lead to the development of convective precipitation (Taylor et al. 2007, 2011; Frye and Mote 2010). This is often observed where local soils are drier than their surroundings such that convection is triggered over dry soils (Taylor et al. 2012). The preference for convection over dry soils has also been attributed to greater decrease in atmospheric stability due to enhancement of surface sensible heat fluxes (Ford et al. 2015a). Over a seasonal time scale, these gradients may influence the location of regional drivers of convective precipitation, such as the dryline (Flanagan et al. 2017).

The low-level jet (LLJ) is the dominant source of moisture transport within the southern Great Plains
(Stensrud 1996; Higgins et al. 1997; Song et al. 2005; Shapiro et al. 2016; Song et al. 2016); however, there is evidence of interactions between the land surface and the LLJ that aid in the development of convective precipitation. In the absence of advection via the LLJ, larger quantities of soil moisture can serve as a local source of necessary moisture for convective precipitation (Frye and Mote 2010). Addition of moisture from wet soils can force changes in precipitation timing and lead to an increase in peak afternoon precipitation and intensity (Wei et al. 2016; Song et al. 2016). When soil moisture is limited, convective precipitation can result from rapid boundary layer growth because of enhanced sensible heat flux and moisture supplied by the LLJ (Ford et al. 2015b). The delicate interplay between synoptic patterns and soil moisture demonstrates a necessity for low-level moisture in which the source is driven by the presence of large-scale moisture transport or lack thereof.

The first goal of this paper is to introduce a modified version of the convective triggering potential, low-level humidity index $(\mathrm{CTP} / \mathrm{HI})$ framework (Findell and Eltahir 2003a) that can be used at varying temporal and spatial scales. The second goal is to provide a climatology of the framework during hydrometeorological extremes in Oklahoma to test the framework's utility at varying spatial and temporal scales. This study uses observations of local soil moisture from the Oklahoma Mesonet, to provide a climatology of the modified framework that is derived from reanalysis data. The chosen temporal period exceeds the minimum number of years (approximately 12) identified by Findell et al. (2015) to adequately study land-atmosphere interactions.

\section{Data and methods}

\section{a. Oklahoma Mesonet}

The Oklahoma Mesonet is an automated mesoscale observing network consisting of over 100 sites that report near-real-time, quality-assured meteorological conditions at 5-min intervals (McPherson et al. 2007) and soil moisture every $30 \mathrm{~min}$ (Illston et al. 2008). All mesonet sensors are calibrated prior to placement and after repair and are replaced at the end of recommended product lifetime, even if no problems are detected (McPherson et al. 2007). Observations from the mesonet have been extensively validated (Scott et al. 2013) to ensure that all observations are of research quality. One limitation arises because of site placement within areas of uniform low-growing vegetation (McPherson et al. 2007) as observations may not be representative of those over other land-cover types. 


\section{1) Mesonet soil Moisture}

Fractional water index (FWI) is a normalized measurement of the Campbell Scientific 229-L sensor response to changes in soil moisture and ranges from 0 (dry soil) to 1 (saturated soil) (Schneider et al. 2003; Illston et al. 2008). The utility of FWI lies within its ability to capture soil wetness independent of soil texture thus standardizing the observation and allowing for intercomparison within the observational network. In this study, wet soils are defined as those with FWI greater than 0.7 , which is considered optimal for plant growth and dry soils defined as having an FWI less than 0.4, which results in water stress (Illston et al. 2008). Soil moisture is monitored via the Campbell Scientific 229-L heat dissipation sensor, which is most commonly deployed at 5,25 , and $60 \mathrm{~cm}$. Soil moisture is measured indirectly by measuring the magnitude of the temperature difference within a ceramic matrix before and after introduction of a heat pulse. The sensor is assumed to be in equilibrium with the soil such that the temperature change is regulated by the water content of the sensor, and thus the soil (Illston et al. 2008). While the sensor performance is similar to that of other available sensors (Cosh et al. 2016), it is slower to respond to changes in soil moisture such that daily variations are muted (Dirmeyer et al. 2016). Further, soil moisture measurements are inaccurate during frozen soil conditions and when the soil texture has a high sand fraction. Quality assurance procedures are performed daily and each sensor's measurements are discarded during the first 21 days of operation to allow it to equilibrate with the surrounding environment (Illston et al. 2008).

Previous coupling studies within Oklahoma (Ford et al. 2015a,b) use 5-cm volumetric water content percentiles to quantify soil wetness. However, the $5-\mathrm{cm}$ measurements have large variability during the summer months (Basara and Crawford 2002; Illston et al. 2004) making this depth less representative of the overall soil column that is contributing to ET; ET is largely driven by plant characteristics and is a vital link in the soilplant-atmosphere continuum (Tindall and Kunkel 1999). Basara and Crawford (2002) showed the greatest relationship occurred between surface latent and sensible heat fluxes and root zone soil moisture at the Norman, Oklahoma, Mesonet site. As such, it is necessary to examine soil moisture depths that are consistent with the root zone of local vegetation. This study primarily uses $25-\mathrm{cm}$ soil moisture measurement depth as most root biomass in this region exists within the top $30 \mathrm{~cm}$ of the soil profile (Weaver 1958; Eggemeyer et al. 2006; Raz-Yaseef et al. 2015). This depth also yields the greatest sample size as some stations do not have sensors beyond $25 \mathrm{~cm}$ because of soil texture or bedrock. Note, however, that similar final conclusions of this study were found using soil moisture at all depths thus only results from $25 \mathrm{~cm}$ are shown.

\section{2) Mesonet precipitation}

The original convective triggering potential/low-level humidity index (CTP/HI) framework (Findell and Eltahir 2003a) is designed to diagnose the potential for afternoon precipitation, therefore only precipitation events that occurred between 2100 and 0300 UTC were included in the analysis. The minimum measurable precipitation at the Oklahoma Mesonet is $0.25 \mathrm{~mm}$ (McPherson et al. 2007) so values below this threshold were counted as no precipitation events. Afternoon precipitation sums were computed for every month at every station. Each month was then assigned a rank based on afternoon precipitation sums for the same month during other years within the climatology. For example, the driest July of all 16 July observations would be given a rank of 1 and the wettest would be assigned a rank of 16 . This monthly rank was assigned to every day within that month for monthly compositing purposes such that if July 2000 at a given station was the wettest July on record, each day in July at that station would be assigned a rank of 16 .

To maintain spatial and temporal consistency and to establish a sufficient climatological analysis length, only stations that were continuously in operation from 1 January 2000 through 31 December 2015 were retained for the analysis. While stations may have been continuously in operation during this time, there may have been periods of time with missing observations because of instrumentation and meteorological issues, so stations that recorded data for less than $85 \%$ of days were omitted. Each station is less than $80 \mathrm{~km}$ from its nearest neighbor such that a missing observation at one point did not significantly impair the spatial resolution of the analyses.

\section{b. NARR}

While mesonet stations provide surface and subsurface data, atmospheric profiles are necessary to calculate CTP/ HI. North American Regional Reanalysis (NARR) data were used to obtain atmospheric profiles of temperature, pressure and specific humidity over Oklahoma during the study period. NARR data assimilate observations with model simulations to generate a 3-hourly gridded dataset with 32-km spatial resolution over the continental United States at 29 vertical levels (Mesinger et al. 2006) and at the time of the analysis was available from 1979 through 2015. Each mesonet station was paired with the nearest NARR gridbox center. This resulted in several stations 
that shared the same grid box. To eliminate redundancy only the station with the least number of missing observations was retained resulting in 93 stations being used for the analysis. These are shown in Fig. 1.

Each NARR vertical profile contains data at 29 levels starting with $1000 \mathrm{mb}(1 \mathrm{mb}=1 \mathrm{hPa})$ (Mesinger et al. 2006). Oklahoma's sloping terrain means that surface pressure can range from approximately $850 \mathrm{mb}$ in the panhandle to over $1000 \mathrm{mb}$ in southeastern Oklahoma, so it is necessary to only use NARR data that are at or above the mesonet surface pressure measurement rather than the beginning the profile at the default $1000-\mathrm{mb}$ pressure. Daily surface pressure observations at each mesonet site in the study were obtained and used as the initial pressure within each vertical profile. This information is necessary for computing CTP and $\mathrm{HI}$ as the computations are performed over layers that are defined by a pressure difference from the surface. Dewpoint observations were obtained by converting NARR profiles of specific humidity were converted to dewpoint using the MetPy software package for Python designed by May et al. (2017).

\section{c. Creation of a CTP/HI dataset}

Vertical profiles of air temperature and dewpoint temperature at 1200 UTC were acquired from the NARR 3-hourly dataset (Mesinger et al. 2006) and linearly interpolated at $1-\mathrm{mb}$ intervals to ensure that calculations of CTP and HI could be performed at the desired pressure levels above surface level. The 1200 UTC time was chosen to remain consistent with the original framework (Findell and Eltahir (2003a). The 25-mb interval used by NARR is too large to adequately capture HI given the two levels used in the calculation are $100 \mathrm{mb}$ apart. The levels that define CTP and especially $\mathrm{HI}$ are intended to represent boundary layer averages. HI only uses observations at two levels, and as such may not fully represent variability within the vertical profile. Even so, they were retained for the current work to maintain consistency with previous studies (Ferguson and Wood 2011; Roundy et al. 2013) that also applied modifications of the framework but retained these level definitions. The methods used by the coupling metric toolkit (Tawfik 2016) were adapted for Python to calculate values of CTP.

CTP is determined using a two-step process:

1) Locating the moist adiabat that intersects the temperature profile $100 \mathrm{mb}$ above ground level (AGL).

2) Integrating the area between this moist adiabat and the temperature profile from 100 to $300 \mathrm{mb}$ AGL.

HI measures the preexisting moisture content of the lower atmosphere and is defined as

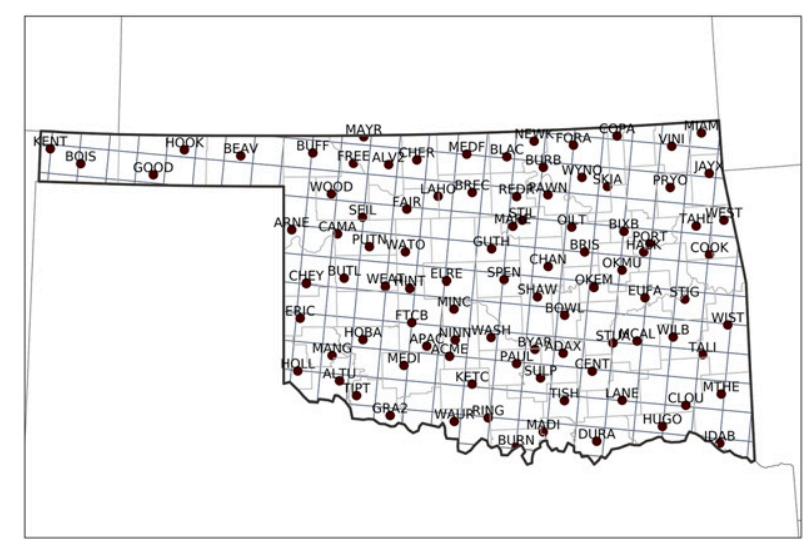

FIG. 1. The Oklahoma Mesonet stations included in the analysis with the NARR grid overlaid.

$$
\mathrm{HI}=\left(T-T_{d}\right)_{150 \mathrm{mb} \mathrm{AGL}}+\left(T-T_{d}\right)_{50 \mathrm{mb} \mathrm{AGL}},
$$

where $T$ is air temperature and $T_{d}$ is the dewpoint temperature. Both CTP and HI were calculated daily at 1200 UTC for the NARR grid box containing each mesonet station during the entire period from 2000 through 2015.

The aforementioned CTP and HI values were derived from reanalysis data, and therefore, we must first quantify their reliability. To perform this verification, we calculate CTP and HI using reanalysis values from the grid box nearest to the Norman mesonet station, which is located near the center of the study domain. Next, CTP and HI values were computed from radiosonde data at the Norman upper-air site and compared to the NARR-derived values; the results are shown in Fig. 2. Overall, the observed values of CTP and HI from the upper-air soundings agree well with the NARR-derived values with correlation coefficients of 0.930 and 0.945 , respectively. One limitation is that the agreement between NARR-derived and observed profiles may be inflated in locations where upper-air stations exist. Because NARR data are a result of the NCEP Eta Model and assimilated observations that include raobs (Mesinger et al. 2006), areas where observations are sparse may be less representative of reality.

\section{d. A revised approach to the CTP/HI climatology}

Ferguson and Wood (2011) computed CTP and HI departures from a latitudinal mean. In Oklahoma, where longitudinal gradients of temperature and precipitation exist at the same latitudes, this approach would result latitudinal anomalies that are biased by longitudinal variability. By contrast, Basara and Christian (2018) applied a standardized anomaly approach to better assess landatmosphere coupling in the southern Great Plains. Thus, the use of standardized anomalies of CTP/HI based on station climatology may capture better the atmospheric 

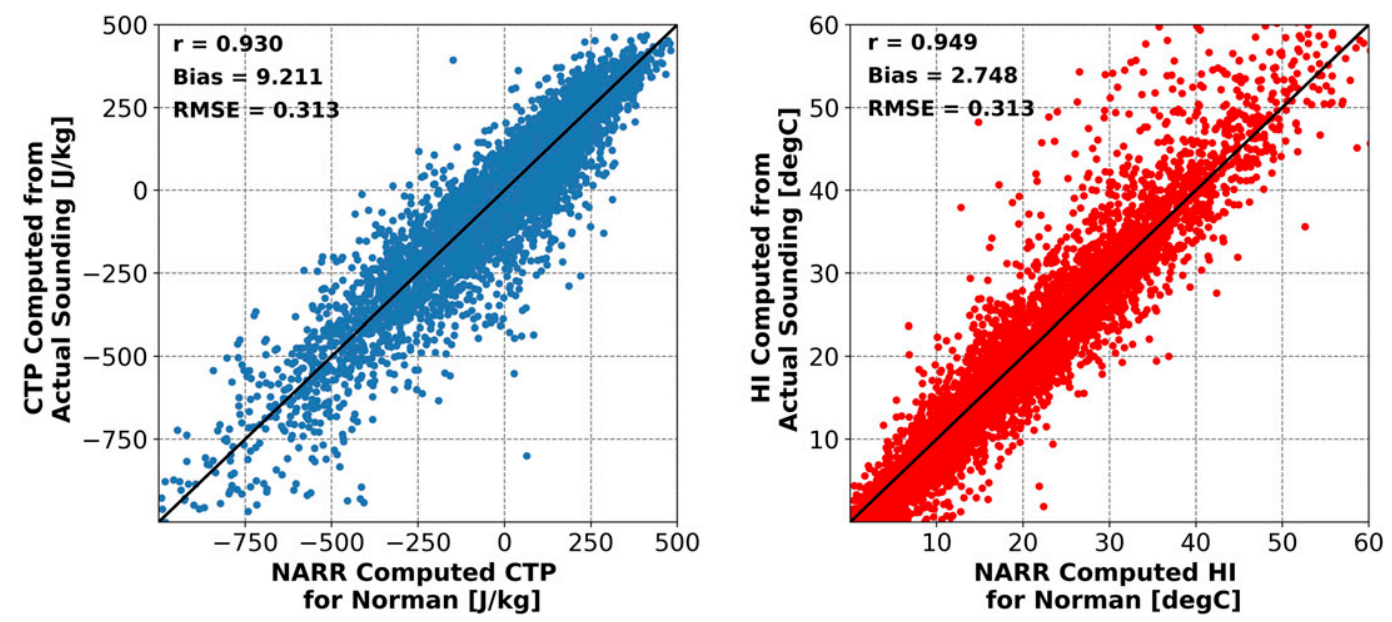

FIG. 2. Scatterplot of CTP and HI computed by NARR and mesonet methods ( $x$ axes) vs CTP and HI computed using observed upper-air sounding data ( $y$ axes) with (left) featuring the relationship between values derived from both methods for CTP $\left(\mathrm{J} \mathrm{kg}^{-1}\right)$ and (right) the relationship between values derived from both methods for $\mathrm{HI}\left({ }^{\circ} \mathrm{C}\right)$. Correlation coefficient, bias, and root-mean-square error are also shown in bold for each plot.

response to different soil moisture states as well as facilitate comparison of the magnitude of responses in both time and space.

\section{1) $\mathrm{CTP} / \mathrm{HI}$ STANDARDIZED ANOMALIES}

Both CTP and HI have annual cycles, with decreased variability during the summer (not shown). Furthermore, the mean values at each station vary across the state. The annual cycle is pronounced such that CTP and HI anomalies must be computed on time scales shorter than 1 month, and the changes in variability necessitate a daily standardized anomaly approach. Daily standardized anomalies result in a small sample size of only 16 years for each day, and the resulting distributions are not Gaussian such that $z$ scores may be biased. As such, a method similar to that of the standardized precipitation index (McKee et al. 1993) using a normal quantile transform (Wilks 2011) was used to obtain $z$ scores. Each daily distribution for each station was transformed into a cumulative probability density function. From the derived $\mathrm{CDF}$, each daily value was assigned a cumulative probability, and this probability was used to compute the $z$ score. These methods were repeated for each day and station to obtain daily $z$ scores that could represent relative differences in the CTP and $\mathrm{HI}$ space among years.

\section{2) PARAMETER SPACE APPROACH}

The CTP/HI parameter space is the space that contains a representation of all possible combinations of CTP and HI $z$ scores. Unique combinations of CTP and $\mathrm{HI}$ provide a characterization of atmospheric moisture and instability during hydroclimate extremes. The primary objective of this approach is to determine if there is consistency in the degree of covariability between the land surface and CTP/HI standardized anomalies during seasonal hydrometeorological extremes rather than to establish set thresholds for coupling regimes. CTP/HI standardized anomaly distributions vary depending upon whether they were computed over wet or dry soils and, so it is hypothesized that seasonal drought and pluvial extremes might have similar distributions to the dry and wet soil cases, respectively, within the parameter space. While other studies focused on using the actual values of CTP and HI at each grid box to identify wet versus dry coupling regimes (Roundy et al. 2013; Roundy and Santanello 2017), this study employs standardized anomalies. Standardized anomalies allow for interstation comparisons of covariability to determine if all dry soil cases for example, are characterized by specific $z$-score (standardized anomaly) pairings in the parameter space. Among stations, the exact values of CTP and HI that yield a specific $z$ score pairing may be highly variable; however, a consistency in behavior within the parameter space could further insight into establishment of future coupling thresholds based on standardized anomalies.

Thus, the four potential bivariate combinations of CTP and $\mathrm{HI}$ anomalies are examined in the $\mathrm{CTP} / \mathrm{HI}$ parameter space in the following analysis and an example distribution is shown in Fig. 3 with the four combinations described as follows:

1) Quadrant I (Q1), CTP below normal/ HI above normal (13.8\% of total points): The atmosphere is generally more stable than normal in the CTP region, while it is drier than normal at the levels where $\mathrm{HI}$ is measured. 

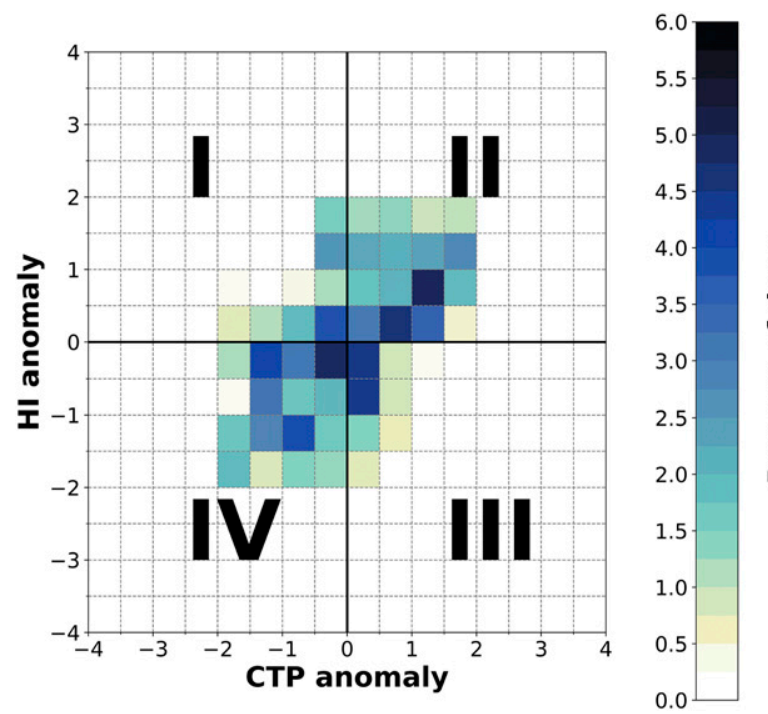

FIG. 3. Example of a CTP-HI parameter space for a region. Quadrants are labeled I-IV in a clockwise direction and represent the 4 possibilities for CTP-HI anomaly pairing. Quadrant I: CTP below normal, HI above normal; quadrant II: CTP above normal, HI above normal; quadrant III: CTP above normal, HI below normal; and quadrant IV: CTP below normal, HI below normal.

2) Quadrant II (Q2), CTP above normal/HI above normal (36.1\% of total points): The atmosphere is more unstable than normal in the CTP region but it is also drier than normal. Nearer to the origin, dry soils drive greater sensible heating and more rapid boundary layer growth that despite limited moisture could result in convective initiation if the PBL reaches the LCL (Ek and Holtslag 2004.) On the other hand, wet soils could result in greater latent heat flux and an increase in moist static energy into an environment that was moisture limited. As such, local destabilization of the lower atmosphere could occur through increased CAPE and a lowering of the LCL (Taylor and Lebel 1998; Pielke 2001; Findell and Eltahir 2003a; Pal and Eltahir 2003; Brimelow et al. 2011). Finally, this quadrant of the parameter space could also result in no convection if the lower atmosphere is too dry for local surface fluxes to overcome the moisture limited regime. During drier-than-normal periods it is expected that more days would fall within this parameter space as dry surface conditions would result in greater sensible heat fluxes, boundary layer mixing, and entrainment of dry air. When the standardized anomalies within this space are exceptionally high, they may be considered too dry for convective precipitation or atmospherically controlled.
3) Quadrant III (Q3), CTP above normal/HI below normal (13.7\% of total points): This regime would be considered primed for convection because of preexisting above-normal instability and abovenormal moisture in the lower troposphere.

4) Quadrant IV (Q4), CTP below normal/HI below normal $(35.8 \%$ of total points): In the moisture abundant, energy limited regime the atmospheric profile is likely near moist adiabatic (Findell and Eltahir 2003a). Precipitation recycling is expected over wet soils through the addition of moist static energy via evapotranspiration. Dry soils could also supply necessary energy and surface-based instability in this case. It is also expected that anomalously wet periods would demonstrate a higher percentage of days occupying this parameter space as wet soils would provide a continuous supply of low-level moisture.

Warm season (May-September) composite soundings for the entire state are shown in Fig. 4 to better demonstrate the profiles that characterize each quadrant.

\section{Results}

\section{a. Climatology of $\mathrm{CTP} / \mathrm{HI}$}

Before computing standardized anomalies, the authors first examined the mean state of CTP and HI within Oklahoma. Monthly mean values of CTP and HI are shown in Fig. 5. In the monthly mean CTP plot, blue denotes values that are less than 0 on average; CTP values below 0 are not conducive for coupling as this would represent a stable profile. Western portions of the domain have the greatest number of months with CTP greater than 0 , and therefore the greatest opportunity for coupling. The entire state experiences mean positive values of CTP during the warm season, or the months of May through September and, based on these results, further analysis will focus primarily on these months for the coupling analysis.

Both CTP and HI means demonstrate month-tomonth variability with a noticeable gradient from east to west. This supports the use of an alternative application of the CTP/HI framework to understand covariability between the land surface and atmosphere and implications for land-atmosphere coupling. Other studies found similar results in different locations of the world and proceeded to establish new thresholds for each regime based upon local climatology (Roundy et al. 2013; Roundy and Santanello 2017). Given the spatial variability in climatology of CTP and HI in Oklahoma, a modified CTP/HI framework was 

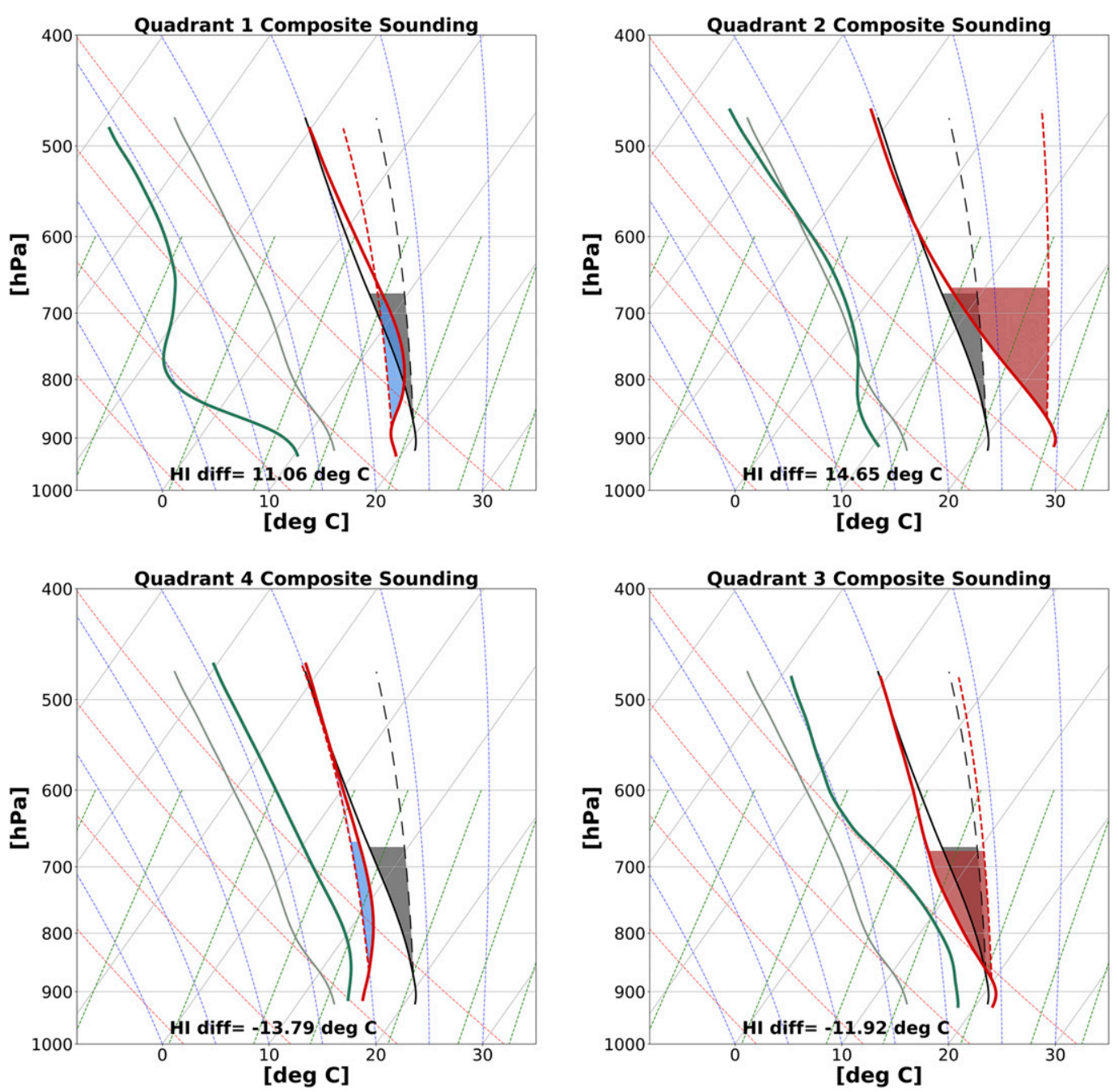

FIG. 4. Composite soundings derived from NARR data for all May-September days from 2000 through 2015 , starting at $50 \mathrm{hPa}$ above the surface, filtered for only those profiles that had CTP and HI $z$ scores one standard deviation above or below normal for combinations of CTP/HI that corresponded to (top left) Q1, (top right) Q2, (bottom left) Q4, and (bottom right) Q3. Red (green) profiles are quadrant composite temperature (dewpoint), while black (gray) represents the overall warm season mean temperature (dewpoint). Red (blue) shading is the area of the profile used to compute CTP and represents positive (negative) CTP. Differences in HI between the overall and quadrant filtered profiles are shown in text at the bottom of each plot.

employed to better understand the covariability between the atmosphere and the land surface.

\section{b. Composite analysis of extreme events}

\section{1) WET VERSUS DRY SOILS WARM SEASON}

The parameter space approach is a useful tool for characterizing and comparing atmospheric preconditioning to convection across the region as $z$ scores are unique to each station's climatology, but can be aggregated to create a statewide composite. CTP and HI $z$ scores were composited for all warm season (May through September) days over dry $(\mathrm{FWI}<0.4)$ or wet $(\mathrm{FWI}>0.7)$ soils. The percentage of CTP/HI $z$-score pairings that were within each $0.5 \times 0.5$ standard deviation bin in the parameter space were computed for the dry and wet soil cases individually. The results of this calculation are shown in Figs. $6 \mathrm{a}$ and $6 \mathrm{~b}$, with the composite difference given in Fig. 6c. Statistical significance was tested through bootstrap resampling with replacement over all warm season days for 1000 iterations in which composite differences for two samples with the same size as the original samples were differenced. Stippling shows those differences that were significant at the $95 \%$ confidence level. 


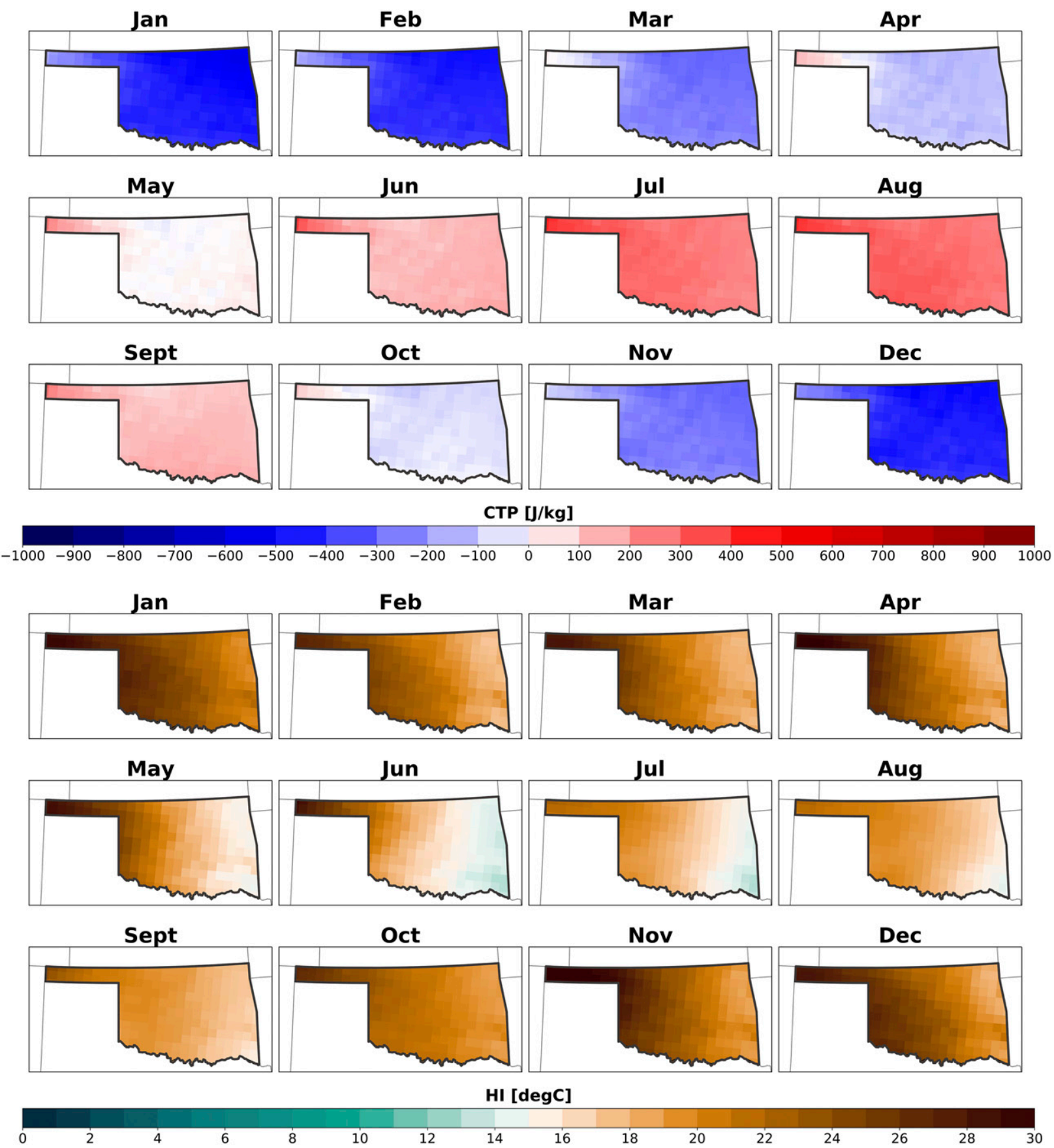

FIG. 5. (top) Monthly climatology of NARR CTP in Oklahoma with blue shades representing negative values and red shades representing positive. (bottom) Monthly climatology of NARR HI in Oklahoma over the period 2000-15 with green shades representing those mean values that are below $15^{\circ} \mathrm{C}$ and brown representing those that are above.

Dry soils have the largest percentage of days within Q2, while wet soils have a greater percentage of days in the other three quadrants. The distinct difference in dry and wet soil parameter spaces highlights an important difference in covariability between the surface and the atmosphere. That is, atmospheric profiles with more negative $\mathrm{HI} z$ scores, and therefore greater moisture content occur more frequently over wet soils while the converse is true for dry soils. CTP $z$ scores follow a similar trend, though the polarity of the distributions between negative (wet soils) and positive (dry soils) $z$ scores is less pronounced than for the case with HI. The 
(a)

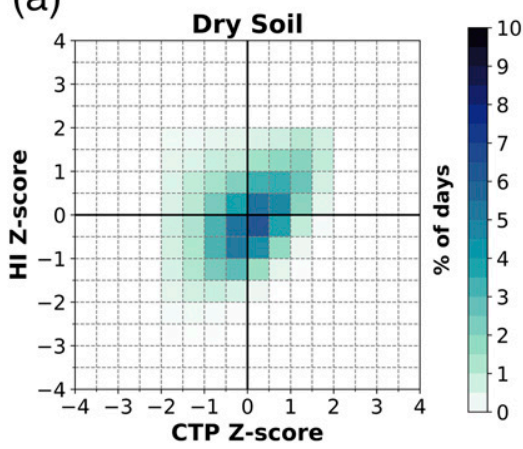

(b)

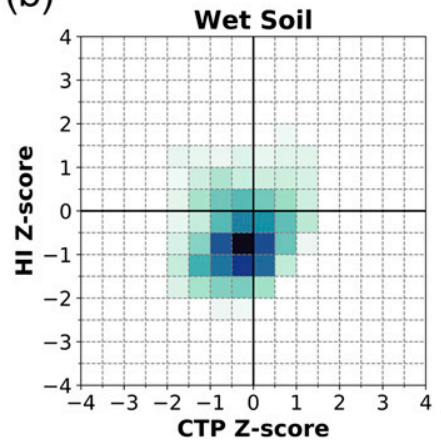

(c)

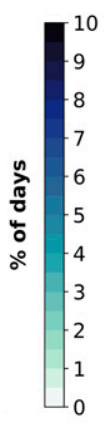

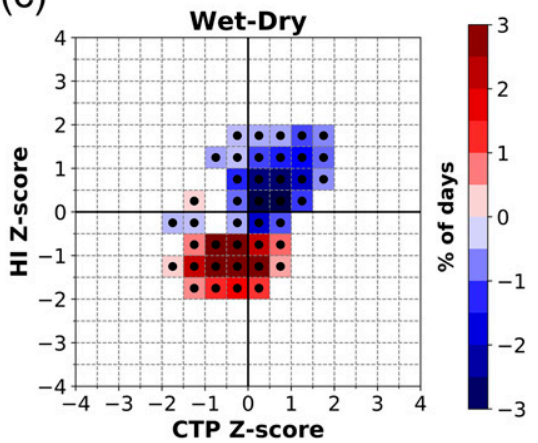

FIG. 6. Distribution of CTP and HI standardized anomalies for warm season days with (a) dry soils (FWI $<0.4)$, (b) wet soils (FWI $>$ 0.7), and (c) composite difference of wet soil bin percentages minus dry soil bin percentage. CTP standardized anomalies are represented on the $x$ axes of each panel, while HI standardized anomalies are represented on the $y$ axes. Fills represent the percentage of days within that region that occupy a given bin with darkest colors at or exceeding $10 \%$ of days for (a) and (b). For (c) colors represent percentages and blue fills indicate bins with a greater percentage of dry soil days and red fills indicate a greater percentage of wet soils days. Black dots in (c) indicate where composite differences are statistically significant $(p<0.05)$ as determined by bootstrap resampling (with replacement).

covariability between the atmosphere and land surface during hydrometeorological extremes presents an important result; however, it is not entirely clear at the temporal and spatial scale used in this study whether this covariability is purely the result of positive feedbacks, a persistent atmospheric state that is driving the wet or dry extremes, or more likely some combination of both.

\section{2) EXTREME YeAR CTP/HI SPACE: PluVial}

Years with heavy rainfall should maintain a wet soil profile, and therefore such years would be expected to have similar distributions within the parameter space to the wet soil composite case. Rainfall during the 2007 and 2015 warm seasons was largely above normal across Oklahoma, and many stations recorded some of the wettest warm seasons for the 16-yr period during these two years (Fig. 7). These two seasons served as a focus for understanding differences in the CTP/HI $z$-score space during hydrometeorological extremes. Composite differences between 2007 and all other warm seasons show a statistically significant $(p<0.05)$ difference in the parameter space similar to the difference between wet and dry soils (Figs. 8a-c). Statewide, HI was anomalously low indicating a moist low-level atmospheric profile. CTP was also below normal and only a small percentage of days featured CTP and HI observations above normal. Figures $9 \mathrm{a}-\mathrm{d}$ illustrate the composite differences at individual stations for the percentage of days in each quadrant during 2007 versus all other years. As in the statewide composite, there are a greater percentage of days in Q4 than normal, but these differences were greatest in the western half of the state.

Widespread anomalously heavy rainfall also occurred during the 2015 warm season, however, the composite parameter space and composite differences are very different from those of 2007. While 2007 had a greater number of days with CTP and HI below normal, 2015 had fewer days (Figs. 8d-f). There were fewer days that had a large magnitude in CTP and HI $z$ scores, and the greatest percentage of days had $\mathrm{HI}$ at or below normal with CTP slightly above normal. Station-based composite differences (Figs. 9e-h) reveal similar results with smaller magnitude deviations from normal. Unlike 2007 (Figs. 9a-d), the greatest differences were in the southeastern part of the state, and there were fewer days in Q4 than normal. Overall, the most consistent increase in percentage of days within a quadrant occurred in Q3, and the greatest reduction was in Q4.

\section{3) EXTREME YEAR CTP/HI SPACE: DROUGHT}

Rainfall was anomalously low during 2006, and 2011 (Fig. 7) with many stations recording some of the driest warm seasons within the 16 -yr period. The largest deficits in precipitation were observed in eastern Oklahoma during 2006 and southwest Oklahoma during 2011. Similar to 2007, the greatest composite differences are observed for percentage of days within Q2 and Q4 during both 2006 (Figs. 8g-i) and 2011 (Figs. 8j-1). As expected based on the dry soil composite, there were a greater number of days in Q2 and fewer in Q4 during the selected drought years than climatology. However, the magnitude of the differences is much greater during 2011 (Figs. 10e-h) than in 2006 (Figs. 10a-d) with a notable decrease in percentage of days within Q3 as well as Q4 to complement the greater percentage of days within Q2 at almost all stations. This indicates that the atmosphere was increasingly dry during this period with a large percentage of days having $\mathrm{HI}$ above normal. These differences prevailed across the entire state. 
2007

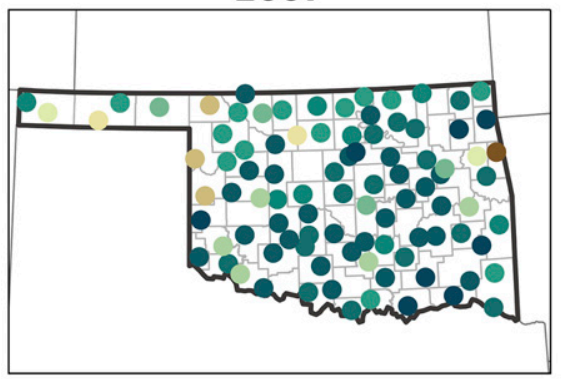

2015

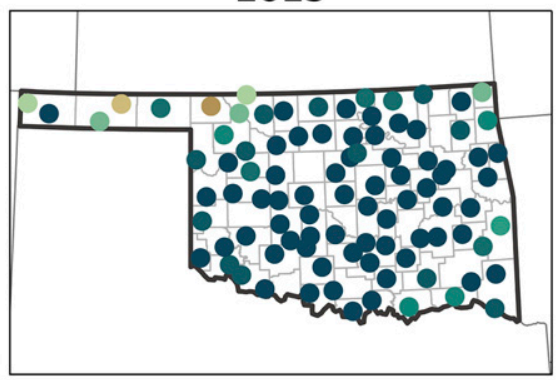

Warm Season Precipitation Rank

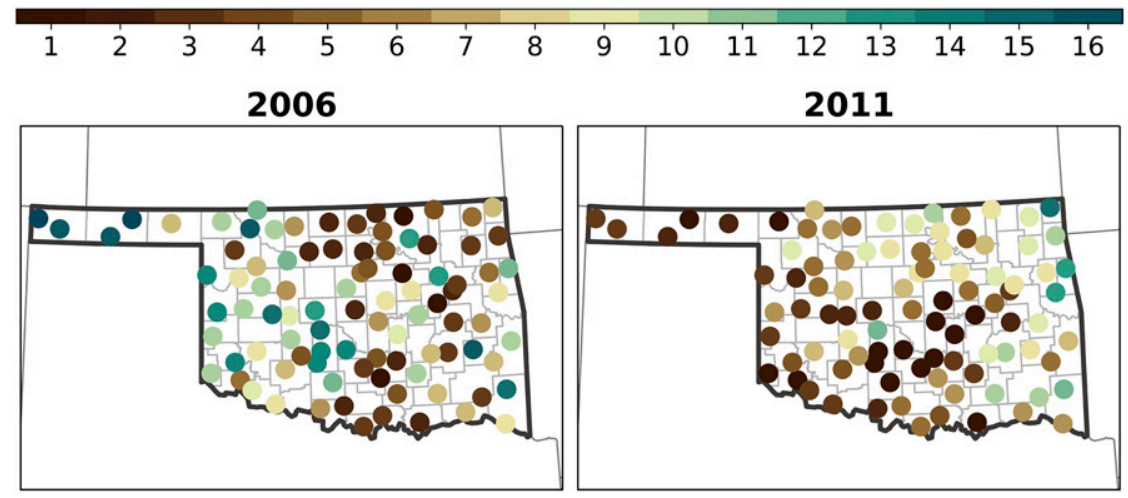

FIG. 7. Rainfall rank by station for (top left) 2007, (top right) 2015, (bottom left) 2006, and (bottom right) 2011. Rank of 1 is shown in brown and indicates the least warm season (MaySeptember) total rainfall for 2000 through 2015, while 16 is in dark green and indicates the greatest warm season total rainfall.

\section{4) Drought EVOlution AND PERCENT OF DAYS IN Q2}

Comparing Drought Monitor (Svoboda et al. 2002) classifications to percentage of days in Q2 at each station during 2011 identifies a clear relationship between drying land surface conditions and the increase in CTP $z$ scores (Fig. 11). At the beginning of June the most intense drought existed in the western half of the state. By July all counties had the greatest percentage of area classified as at least D0 (abnormally dry). Those counties that experienced some of the greatest intensification of drought, particularly in northeast Oklahoma, also had some of the greatest percentages of days in Q2 during June. Similar results occurred in August and September. Furthermore, the greatest percentage of days in Q2 occurred where drought was most intense or showed the greatest intensification.

\section{Discussion}

The CTP/HI framework provides a useful foundation for understanding covariability between the land surface and atmosphere. As with previous work, it is most useful when modified to capture local climatology. CTP standardized anomalies diagnose the instability of the local atmosphere while HI standardized anomalies supply information regarding low-level moisture relative to a temporal mean. The point-based evaluation of these parameters allows for adjustments to local variability, while the standardized anomaly approach makes it possible to upscale the point-based computations such that interstation comparisons can be made. Overall, this approach highlights the nature of the covariability between the land surface and atmosphere during hydrometeorological extremes and how this covariability evolves in both space and time using a consistent metric.

Past studies have shown that spatial and temporal scale is important for diagnosing whether positive or negative feedbacks are occurring, and thus the nature of land-atmosphere coupling (Guillod et al. 2015). The current metric can reconcile these differences through its flexibility of application from diurnal to annual scales as well as point-based to regional composites. The comparison to in situ soil moisture observations provides a source of verification with land surface observations and its application across varying temperature and precipitation climatologies supports its ability 
(a)

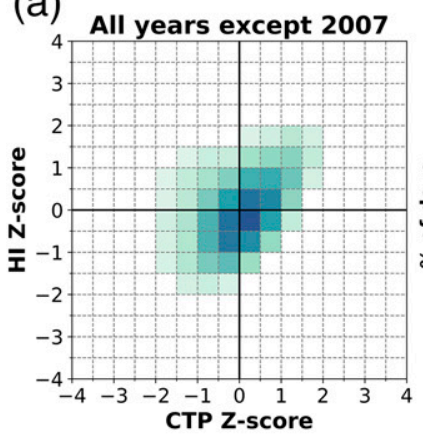

(d)

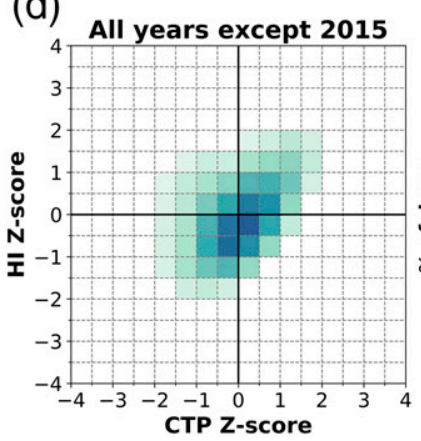

(g)
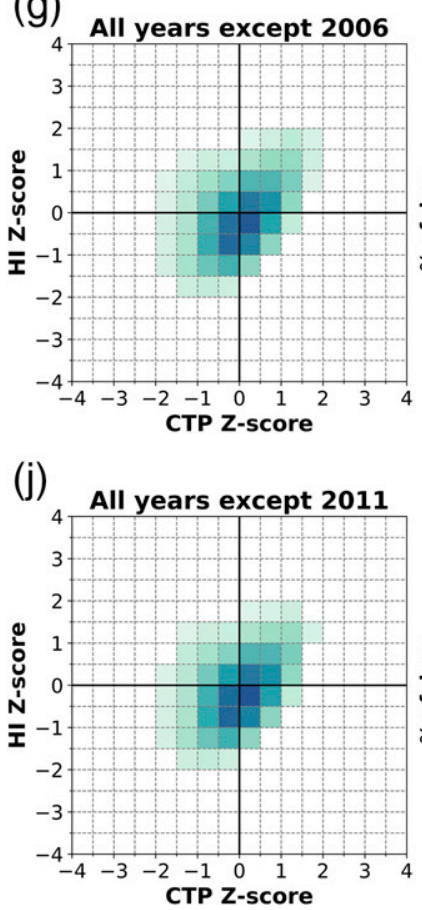

(b)
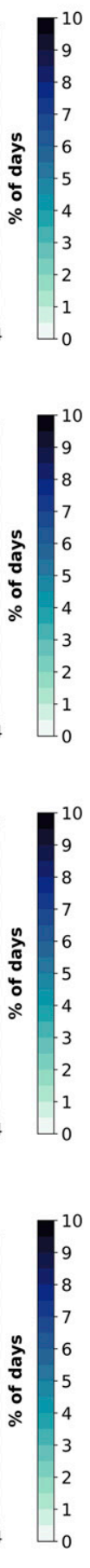

(e)

(k)
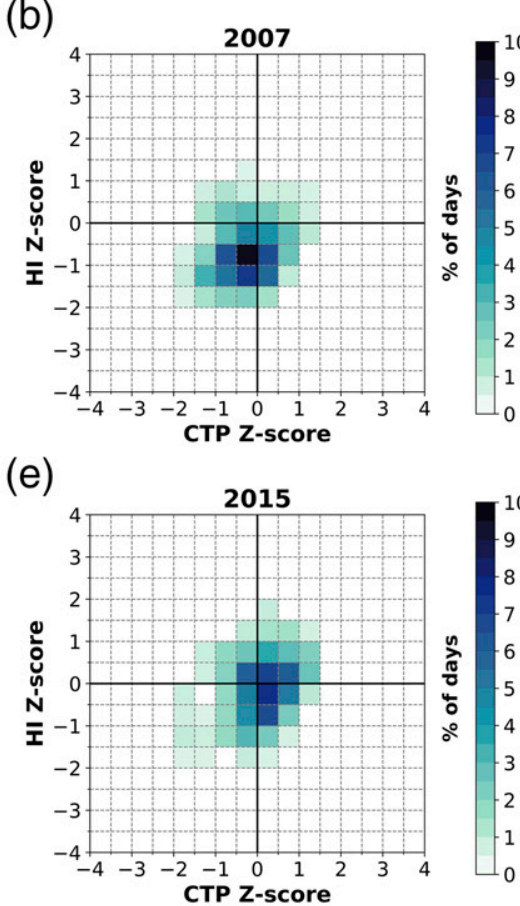

(h)
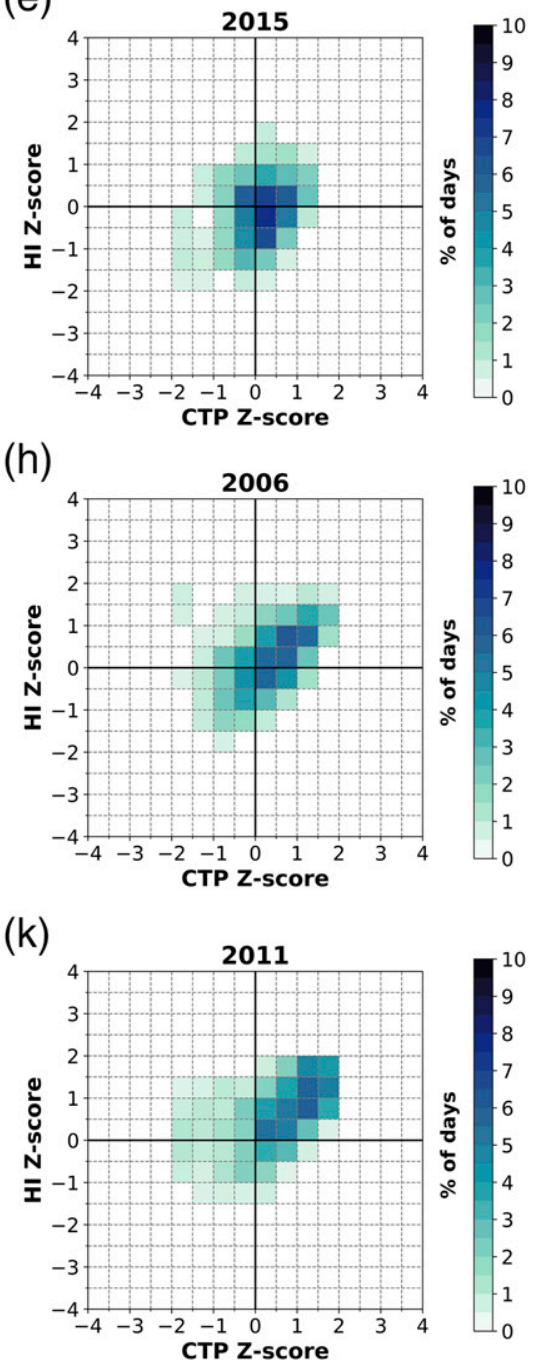

(c)

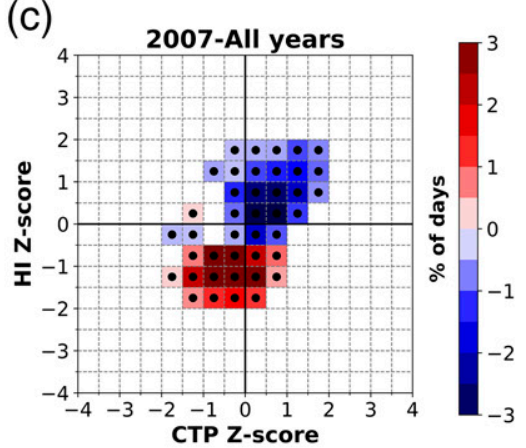

(f)
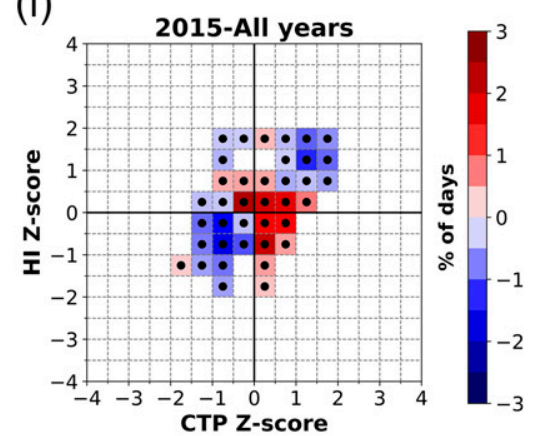

(i)

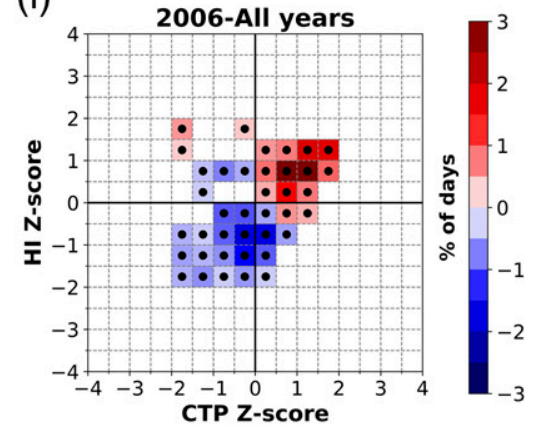

(l)

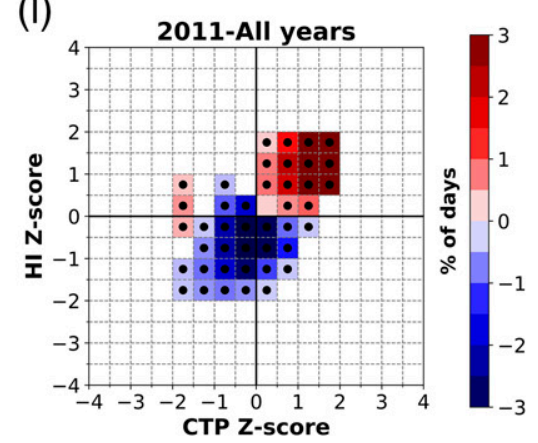

FIG. 8. As in Fig. 6, but for (a) all years except 2007, (b) 2007, and (c) 2007 minus all years. (d)-(f) As in (a)-(c), but for 2015, (g)-(i) as in (a)-(c), but for 2006, and (j)-(1) as in (a)-(c), but for 2011.

to be applied to future work over larger spatial domains. As such, both point-scale and regional-scale coupling can be explored using a single unified framework.

The revised CTP/HI framework based upon standardized anomalies sufficiently reflects the persistence of anomalies in atmospheric stability and moisture during different hydrometeorological extremes as demonstrated by the analysis of drought and pluvial years. Composite soundings for each quadrant also reflect these distinct differences. 
(a)

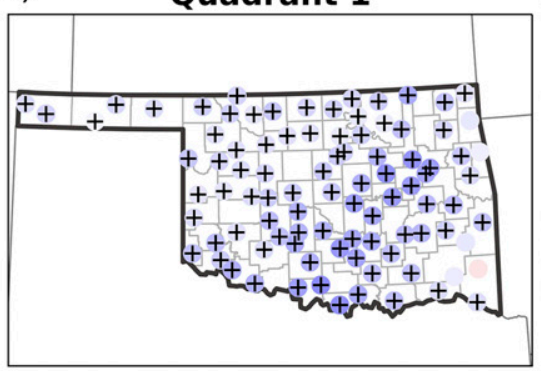

(b)

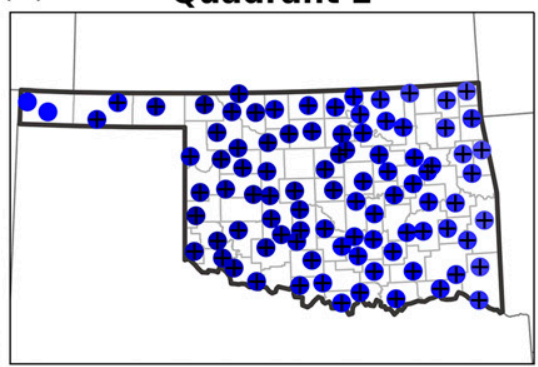

\% difference (2007)

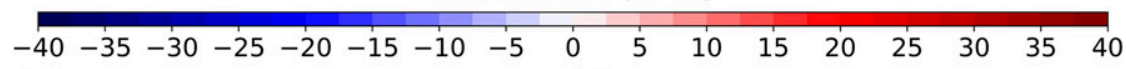

(c)

Quadrant 4

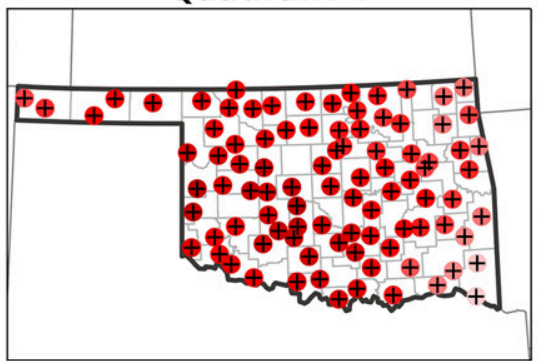

(e)

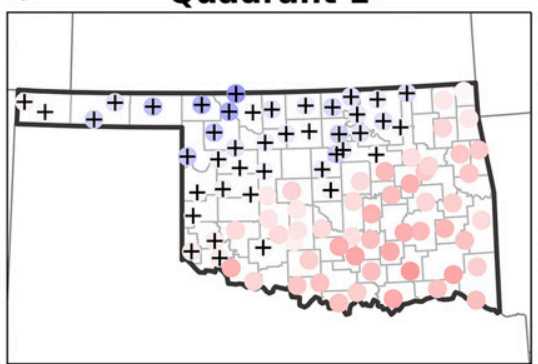

(d)

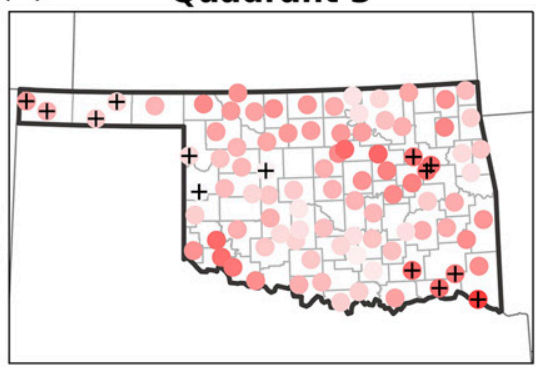

(f)

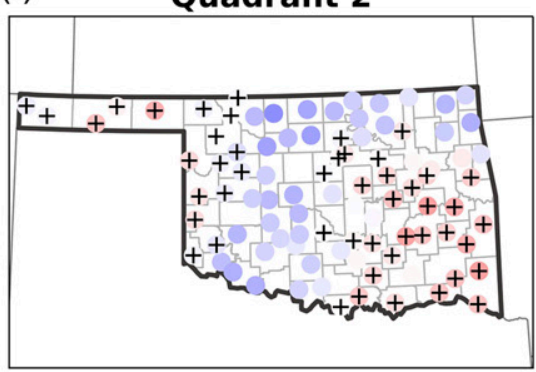

$\%$ difference (2015)

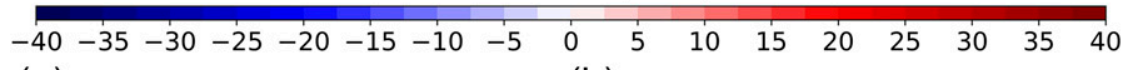

(g)

(h)
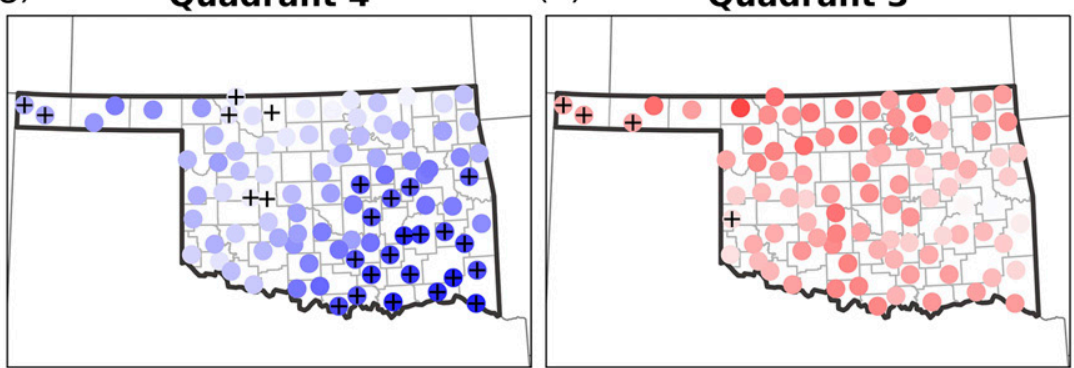

FIG. 9. (a) Composite difference between percentage of days in Q1 during 2007 and all other years per station. (b) As in (a), but for Q2. (c) As in (a), but for Q4. (d) As in (a), but for Q3. Black cross indicates the composite difference is statistically significant $(p<0.05)$ via a bootstrapping test. (e)-(h) As in (a)-(d), but for 2015. 
(a)

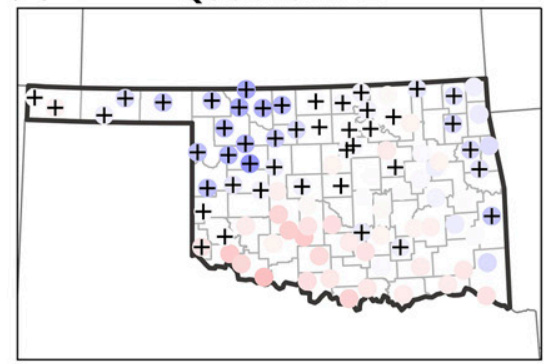

(b)

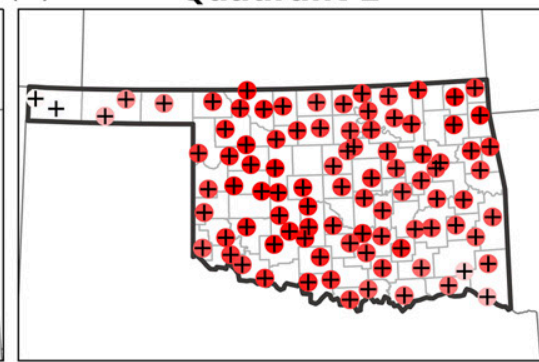

\% difference (2006)

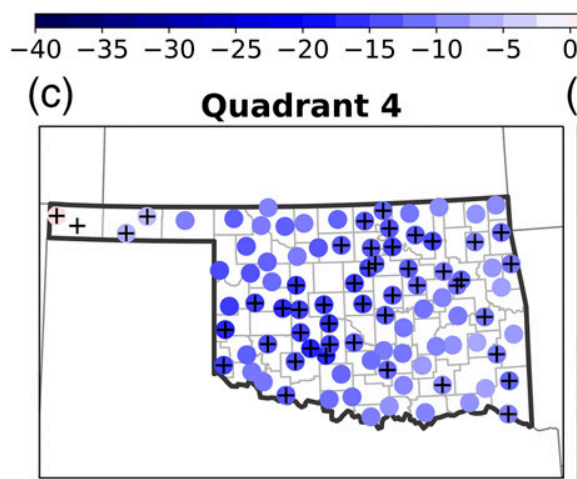

(d)

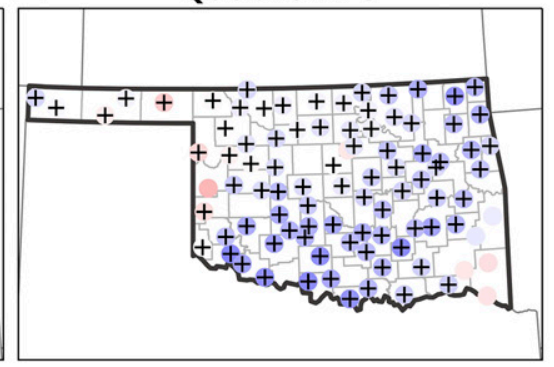

(e)

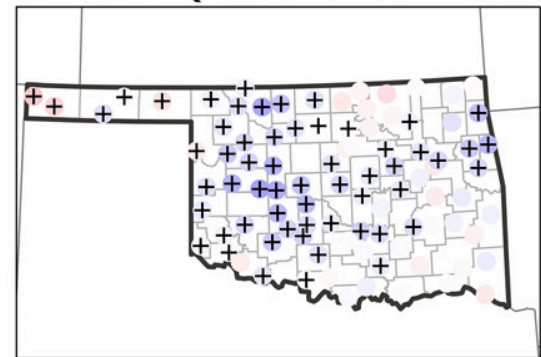

(f)

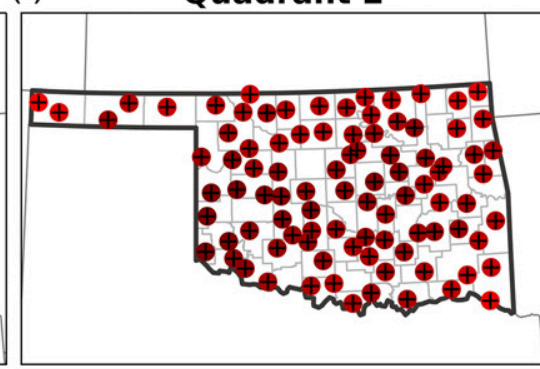

\% difference (2011)

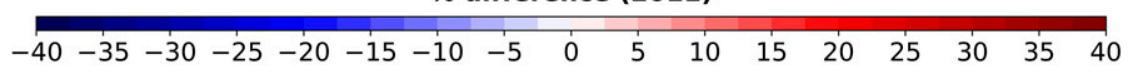

(g) Quadrant 4

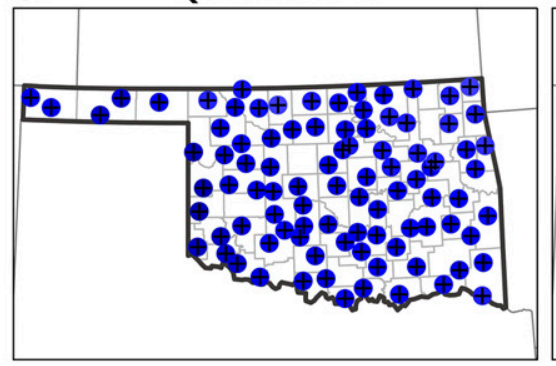

(h)

Quadrant 3

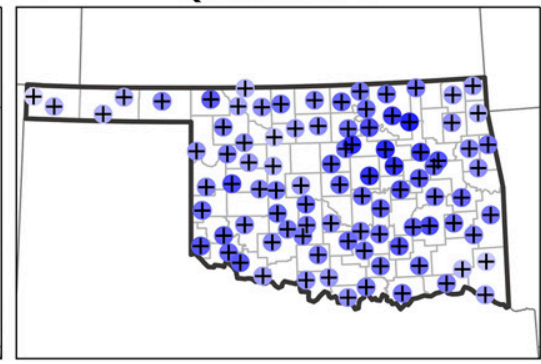

FIG. 10. As in Fig. 9, but for (a)-(d) 2006 and (e)-(h) 2011.

While 2007 and 2015 were both characterized by anomalously heavy warm season precipitation, the overall atmospheric conditions varied greatly between the two years. Where 2007 had a greater percentage of days in Q4 than normal, 2015 had a greater percentage in Q3. Furthermore, the composite differences between 2007 and climatology were significantly greater than those of 2015. The difference between these years was 


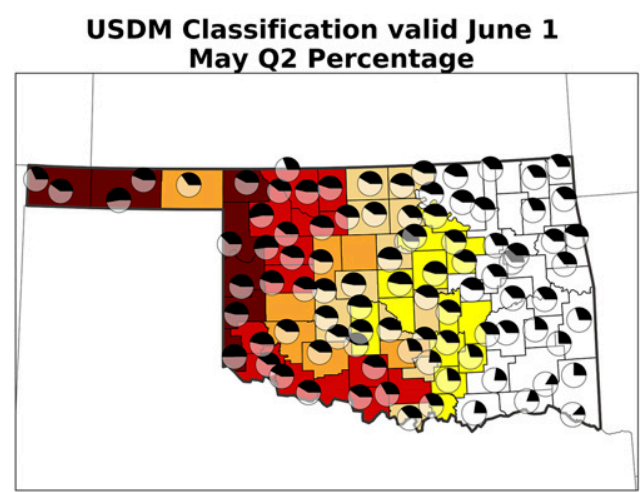

USDM Classification valid Aug 1 July Q2 Percentage

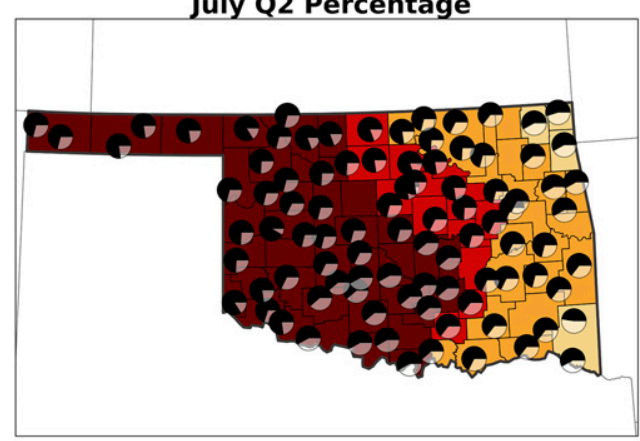

USDM Classification valid July 1 June Q2 Percentage

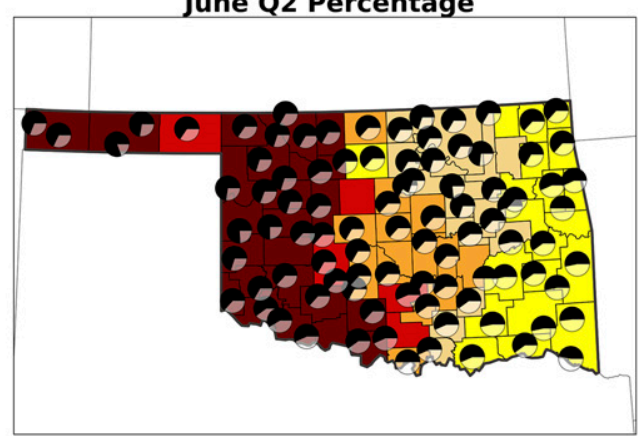

USDM Classification valid Sept 1 Aug Q2 Percentage

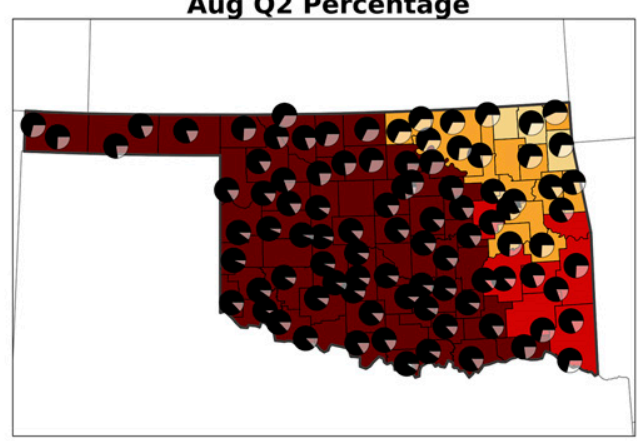

D2: Severe Drought

D3: Extreme Drought

D4: Exceptional Drought

FIG. 11. 2011 U.S. Drought Monitor Classification by county for classification with greatest areal percentage valid on (top left) 1 Jun, (top right) 1 Jul, (bottom left) 1 Aug, and (bottom right) 1 Sep. The percentage of days in Q2 during the preceding month is represented by the black portion of the pie chart for each station, while the percentage of days within the rest of the quadrants is represented in gray.

unexpected, and might indicate fundamental differences in both the large-scale drivers of precipitation and the interaction of the land surface with these drivers. Heavy precipitation is often a result of complex interactions between the land surface and large-scale features such as the low-level jet rather than the land surface acting alone, making it difficult to quantify the relative contributions from the land surface (Frye and Mote 2010; Ford et al. 2015a,b; Song et al. 2016; Welty and Zeng 2018). Pluvial years in the southern Great Plains are often driven by characteristic synoptic patterns, and these patterns were responsible for the anomalous precipitation during 2015 but not during 2007 (Flanagan et al. 2018). During 2007, the same patterns were not in place, but a persistent upper-level low over Texas played a significant role (Dong et al. 2011). Even with large-scale drivers, it is thought that land-atmosphere feedbacks also played a nonnegligible role in precipitation persistence (Dong et al. 2011; Su et al. 2014; Wei et al. 2016; Su and Dickinson 2017). Most moisture during extreme precipitation events can be traced to evaporation over large bodies of water (Dirmeyer and Kinter 2010), though nonlocal land surface feedbacks can alter the supply of moisture (Koster et al. 2016), with land surface evaporation upstream augmenting preexisting moisture (Teufel et al. 2017).

Precipitation anomalies during 2015 were widespread across the Great Plains, while during 2007 they were more concentrated within Oklahoma and Texas. Positive feedbacks in time and negative feedbacks in space can both contribute to land-atmosphere coupling and are not mutually exclusive (Guillod et al. 2015). The long-term means presented here mute those periods when heterogeneities in soil moisture may have driven localized negative feedbacks. However, in the case of 2007, they might indicate some degree of persistence via 

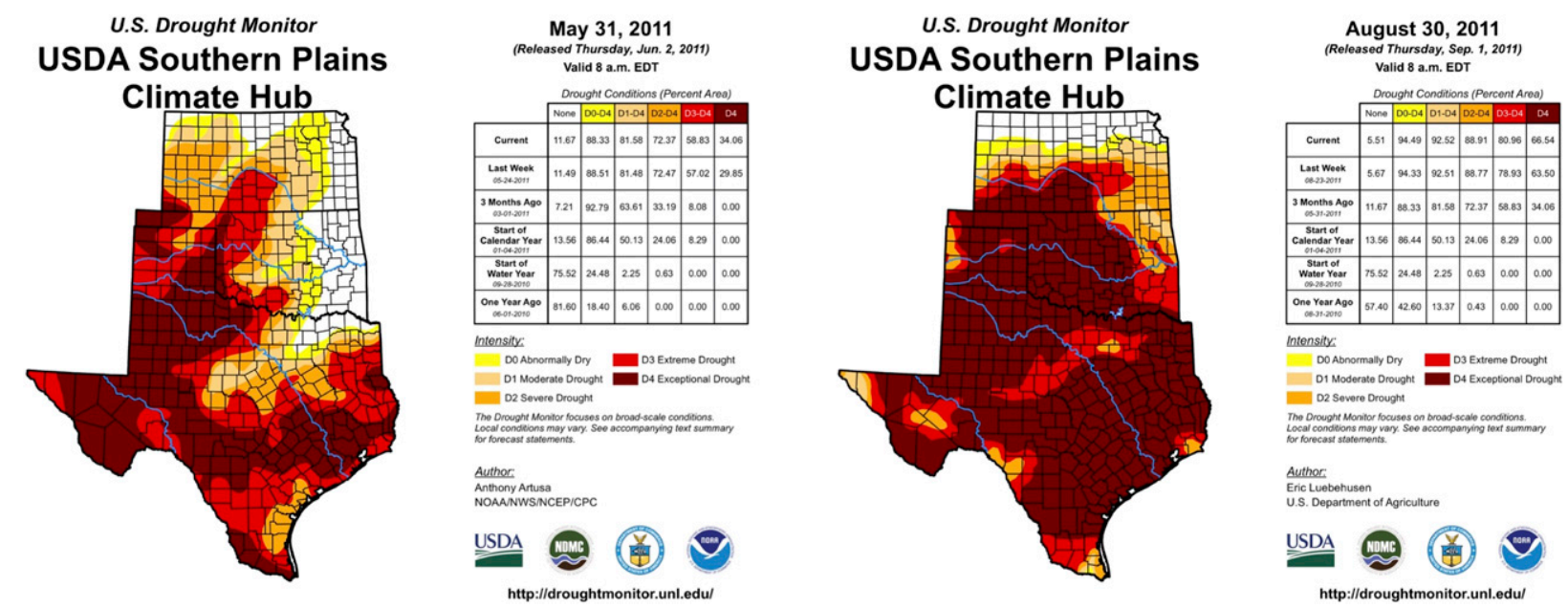

FIG. 12. U.S. Drought Monitor Classifications for (left) 31 May and (right) 30 Aug 2011. (Image credit: U.S. Drought Monitor; Svoboda et al. 2002.)

positive feedbacks over time, as Roundy et al. (2013) showed that the duration wet coupling events increases with increasing soil moisture. Future work will explore whether land-atmosphere feedbacks can be identified during these pluvial periods by employing the framework at shorter time scales to analyze the duration of periods with strong covariability, and during periods when soils were more heterogeneous to better understand the role of spatial feedbacks. A final key limitation to the study is that much of the precipitation within this region is driven by nocturnal convection (Wallace 1975), which is not captured by this framework as it is afternoon-convection focused (Findell and Eltahir 2003a). Differences in diurnal precipitation timing for 2007 and 2015 may have also influenced the nature of the results presented.

Drought years showed more consistency than wet years within the $\mathrm{CTP} / \mathrm{HI} z$-score parameter space, and results generally agreed with those for days with dry soils. Sensitivity of forecast skill to initial soil moisture conditions increases with magnitude of soil moisture anomalies (Koster et al. 2011) while evapotranspiration becomes more responsive to changes in soil moisture when soils are drier (Phillips and Klein 2014; Williams et al. 2016). It is thus no surprise that we find greater consistency in surface-atmosphere covariability during drought periods.

The monthly breakdown of drought evolution and percentage of days within the Q2 space (Fig. 11) showed a large majority of days display above-normal CTP and HI during the preceding month in the regions where drought was already present, or where drought intensified rapidly. Furthermore, the presence of drought in western Oklahoma and the Texas Panhandle during June, July, and August of 2011 (Fig. 12), may have resulted in a reduction of precipitation farther to the east, propagating drought via nonlocal feedbacks, via similar mechanisms to those discussed in Koster et al. (2016).

During late spring of 2011 in Texas, anomalous westerly winds advected warm dry air from the Mexican plateau, which resulted in anomalously warm dry air being observed at $850 \mathrm{hPa}$ (Fernando et al. 2016). Because of zonal topographic gradients, dry soils in the Texas Panhandle and western Oklahoma might have similar implications for the level in which HI is measured in eastern Oklahoma assuming a mean westerly flow and minimal vertical transport. As such, elevated percentages of Q2 in western Oklahoma (Fig. 11) that slowly propagate eastward preceding the eastward propagation of drought certainly suggest some degree of covariability at the local and nonlocal scale. This is evidenced by examining the monthly evolution of persistence within Q2 as drought intensified and propagated. The persistence in above-normal CTP and HI indicate a progressively drier atmosphere that becomes more hostile to convective precipitation. Drought intensity was greater in western Oklahoma at the beginning of July, but the percentage of days in Q2 was above $60 \%$ for most stations from southwest Oklahoma to northeast Oklahoma. Few stations had Q2 percentages below $60 \%$ in southeast Oklahoma during July, and by August many were above $80 \%$. This accompanied the intensification of drought from D0 (abnormally dry) on 1 July to D3 (extreme drought) by 1 September in the southeastern part of the state. The August to September change in drought is weakest where the Q2 percentages are also weakest during August.

When all years are considered, this interannual variability in mean warm season CTP and HI $z$ scores is evident (Fig. 13). Drought years $(2006,2011,2012)$ have 


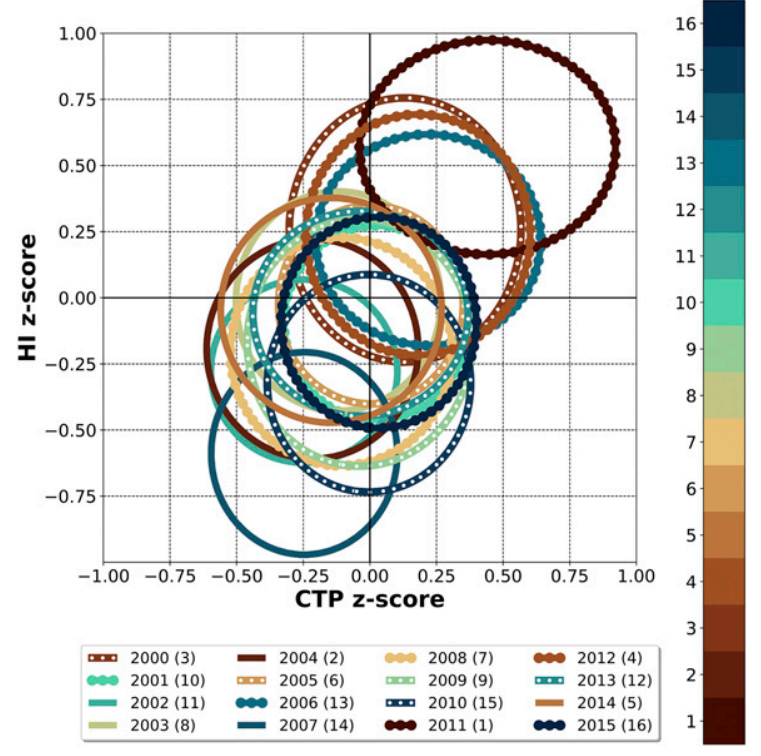

FIG. 13. Warm season (May-September), statewide climatology of CTP and HI $z$ scores by year. The center of each ellipse represents the mean $z$ score for that year, while the width represents one standard deviation in CTP $z$ scores for the year and the height represents one standard deviation in $\mathrm{HI} z$ scores for the year. Numbers in parentheses next to each year in the legend represent the statewide warm season precipitation rank for the year with 1 being the driest and 16 being the wettest.

similar mean tendencies toward Q2, while wet years are more variable. During the pluvial cases, large-scale atmospheric drivers played a significant role in generating anomalous precipitation; however, covariability between the land surface and atmosphere during 2007 is much more consistent with the wet soil case.

This study shows significant differences in the atmospheric profile between quadrants, demonstrating the framework's ability to capture different atmospheric preconditioning for different hydrometeorological extremes. When drought versus pluvial years are considered, the large differences in the distributions of CTP and $\mathrm{HI} z$ scores between the two displays some degree of covariability between precipitation extremes observed at the land surface, and CTP/HI $z$-score extremes within the atmosphere.

One unexpected result is the large difference in distributions of CTP/HI $z$ scores for 2007 and 2015, as well as the overall tendency for extreme $z$ scores to be observed during hydrometeorological extremes. The statistical significance of the difference between extreme years and climatology suggests that there is covariability between the land surface and CTP/HI $z$ scores during hydrometeorological extremes at the seasonal scale. Such results are somewhat contradictory of previous analyses with applications of the CTP/HI framework
(Roundy et al. 2013; Roundy and Santanello 2017) that suggest coupling is more likely for cases when CTP and $\mathrm{HI}$ are less extreme. The analysis presented here is performed at the seasonal time scale, and as such does not capture the smaller time scales at which coupling was observed in Roundy et al. (2013).

\section{Conclusions}

The primary objective of this study is to 1 ) introduce a modified CTP/HI framework that is flexible to various datasets and local climatology and 2) present initial results from application of the framework at a seasonal to interannual scale. The modified framework reflects the varying instability and moisture characteristics of the atmosphere for each quadrant, and shows how these characteristics covary with soil moisture and for precipitation extremes.

While a difference in atmospheric preconditioning, as represented by $\mathrm{CTP} / \mathrm{HI}$, is identified for drought, pluvial, and soil moisture extremes, these patterns are far more consistent for drought than pluvial cases. The difference in distributions of CTP/HI standardized anomalies from year to year further displays interannual variability in coupling metrics identified in previous work (Guo and Dirmeyer 2013; Basara and Christian 2018). Within this interannual variability is a relatively consistent separation of drought and pluvial distributions in the CTP/HI parameter space. While this study is focused on seasonal time scales, several important results arose from this study:

1) The composite differences in CTP and HI $z$ scores over dry versus wet soils are statistically significant, suggesting covariability between the atmosphere and land surface is manifested in the CTP/HI $z$-score distributions.

2) Similarly, the magnitudes of the differences in CTP/ $\mathrm{HI} z$-score distributions for drought versus pluvial years demonstrates a persistence in CTP/HI $z$ scores that is similar among these extreme years.

3) There is greater variability in CTP/HI $z$ scores among pluvial years than for drought years likely because of differences in the large-scale atmospheric drivers of pluvial events as well as the strength of the role of land-atmosphere coupling in these cases. Such differences between pluvial years warrant further exploration.

4) During 2011, the percentage of days within Q2 showed both local and nonlocal covariability with drought intensity. The greatest percentage of days within Q2 began where drought was most intense at the onset of the warm season and spread eastward with drought, demonstrating the utility of the $\mathrm{CTP} / \mathrm{HI}$ 
$z$-score framework for evaluating the role of landatmosphere coupling in evaluating drought intensification and propagation. This framework may hold fundamental clues about the evolution of atmospheric conditions that are favorable for drought onset before the land surface responds, providing a greater opportunity for seasonal and subseasonal predictability of drought and greater lead time for agricultural stakeholders.

5) There exists significant interannual variability in the CTP/HI $z$-score parameter space (Fig. 13). While many years were clustered together, there were several years that also stand out; not surprisingly, these were the years with the greatest precipitation extremes including 2007, 2006, and 2011. Such findings demonstrate the utility of the revised CTP/HI framework for diagnosis and prediction of hydroclimate extremes, especially in drought cases.

The current study presents a modified CTP/HI framework that depends on local climatology and thus can be compared across time and space. This framework demonstrates distinct differences in the distribution of $\mathrm{CTP} / \mathrm{HI} z$ scores across hydrometeorological extremes, especially for pluvial years. As noted in previous work, coupling often occurs over shorter time scales than the seasonal scale used here, and therefore future work will explore the variations in CTP and HI $z$ scores at finer temporal scales to better understand the differences observed during pluvial years as well as the relative contribution of coupling to both drought and pluvial extremes.

Acknowledgments. This work was supported, in part, by the Agriculture and Food Research Initiative Competitive Grant (2013-69002) from the USDA National Institute of Food and Agriculture and support through an agreement with the USDA Southern Plains Climate Hub. C.R.F was supported by NASA Award NNX16AM13G. The authors thank Paul Dirmeyer and the anonymous reviewers whose comments improved the quality of the manuscript.

\section{REFERENCES}

Atlas, R., N. Wolfson, and J. Terry, 1993: The effect of SST and soil moisture anomalies on GLA model simulations of the 1988 U.S. summer drought. J. Climate, 6, 2034-2048, https://doi.org/ 10.1175/1520-0442(1993)006<2034:TEOSAS > 2.0.CO;2.

Basara, J. B., and K. C. Crawford, 2002: Linear relationships between root-zone soil moisture and atmospheric processes in the planetary boundary layer. J. Geophys., 107, 4274, https:// doi.org/10.1029/2001JD000633.

_ - and J. I. Christian, 2018: Seasonal and interannual variability of land-atmosphere coupling across the southern Great Plains of North America using the North American regional reanalysis. Int. J. Climatol., 38, 964-978, https://doi.org/10.1002/ joc.5223.

Brimelow, J. C., J. M. Hanesiak, and W. R. Burrows, 2011: Impacts of land-atmosphere feedbacks on deep, moist convection on the Canadian prairies. Earth Interact., 15, https://doi.org/ 10.1175/2011EI407.1.

Cosh, M. H., and Coauthors, 2016: The Soil Moisture Active Passive Marena, Oklahoma, In Situ Sensor Testbed (SMAP-MOISST): Testbed design and evaluation of in situ sensors. Vadose Zone J., 15 (4), https://doi.org/10.2136/vzj2015.09.0122.

Dirmeyer, P. A., 2006: The hydrologic feedback pathway for landclimate coupling. J. Hydrometeor., 7, 857-867, https://doi.org/ 10.1175/JHM526.1.

_ 2011: The terrestrial segment of soil moisture-climate coupling. Geophys. Res. Lett., 38, L16702, https://doi.org/10.1029/ 2011GL048268.

- and Coauthors, 2016: Confronting weather and climate models with observational data from soil moisture networks over the United States. J. Hydrometeor., 17, 1049-1067, https://doi.org/10.1175/JHM-D-15-0196.1.

Dong, X., and Coauthors, 2011: Investigation of the 2006 drought and 2007 flood extremes at the southern Great Plains through an integrative analysis of observations. J. Geophys. Res., 116, D03204, https://doi.org/10.1029/2010JD014776.

Eggemeyer, K. D., T. Awada, D. A. Wedin, F. E. Harvey, and X. Zhou, 2006: Ecophysiology of two native invasive woody species and two dominant warm-season grasses in the semiarid grasslands of the Nebraska Sandhills. Int. J. Plant Sci., 167, 991-999, https://doi.org/10.1086/505797.

Ek, M. B., and A. A. M. Holtslag, 2004: Influence of soil moisture on boundary layer cloud development. J. Hydrometeor., 5, 86-99, https://doi.org/10.1175/1525-7541(2004)005<0086:IOSMOB > 2.0.CO;2.

Ferguson, C. R., and E. F. Wood, 2011: Observed land-atmosphere coupling from satellite remote sensing and reanalysis. J. Hydrometeor., 12, 1221-1254, https://doi.org/10.1175/ 2011JHM1380.1.

Fernando, D. N., and Coauthors, 2016: What caused the spring intensification and winter demise of the 2011 drought over Texas? Climate Dyn., 47, 3077-3090, https://doi.org/10.1007/ s00382-016-3014-x.

Findell, K. L., and E. A. B. Eltahir, 2003a: Atmospheric controls on soil moisture-boundary layer interactions. Part I: Framework development. J. Hydrometeor., 4, 552-569, https://doi.org/ 10.1175/1525-7541(2003)004<0552:ACOSML>2.0.CO;2.

_- and —_, 2003b: Atmospheric controls on soil moistureboundary layer interactions. Part II: Feedbacks within the continental United States. J. Hydrometeor., 4, 570-583, https://doi.org/10.1175/1525-7541(2003)004<0570:ACOSML> 2.0.CO;2.

_ , P. Gentine, B. R. Lintner, and B. P. Guillod, 2015: Data length requirements for observational estimates of land-atmosphere coupling strength. J. Hydrometeor., 16, 1615-1635, https:// doi.org/10.1175/JHM-D-14-0131.1.

Fischer, E. M., S. I. Seneviratne, D. Luthi, and C. Shar, 2007a: Contribution of land-atmosphere coupling to recent European summer heat waves. Geophys. Res. Lett., 34, L06707, https://doi.org/10.1029/2006GL029068.

,, P. L. Vidale, D. Luthi, and C. Shar, 2007b: Soil moisture-atmosphere interactions during the 2003 European summer heat wave. J. Climate, 20, 5081-5099, https://doi.org/ 10.1175/JCLI4288.1. 
Flanagan, P. X., J. B. Basara, J. Otkin, and B. G. Illston, 2017: The effect of the dryline and convective initiation on drought evolution over Oklahoma during the 2011 drought. Adv. Meteor., 2017, 8430743, https://www.doi.org/10.1155/2017/8430743.

,-- J. Furtado, and X. Xiao, 2018: Primary atmospheric drivers of pluvial years in the United States Great Plains. J. Hydrometeor., 19, 643-658, https://doi.org/10.1175/JHM-D17-0148.1.

Ford, T. W., A. D. Rapp, S. M. Quiring, and J. Blake, 2015a: Soil moisture-precipitation coupling: Observations from the Oklahoma Mesonet and underlying physical mechanisms. Hydrol. Earth Syst. Sci., 19, 3617-3631, https://doi.org/10.5194/ hess-19-3617-2015.

,-- , and -2015 b: Does afternoon precipitation occur preferentially over dry or wet soils in Oklahoma? J. Hydrometeor., 16, 874-888, https://doi.org/10.1175/JHM-D-14-0005.1.

Frye, J. D., and T. L. Mote, 2010: Convection initiation along soil moisture boundaries in the southern Great Plains. Mon. Wea. Rev., 138, 1140-1151, https://doi.org/10.1175/2009MWR2865.1.

Guillod, B. P., B. Orlowsky, D. G. Miralles, A. J. Teuling, and S. I. Seneviratne, 2015: Reconciling spatial and temporal soil moisture effects on afternoon rainfall. Nat. Commun., 6, 6443, https://doi.org/10.1038/ncomms7443.

Guo, Z., and Coauthors, 2006: GLACE: The Global Land-Atmosphere Coupling Experiment. Part II: Analysis. J. Hydrometeor., 7, 611625, https://doi.org/10.1175/JHM511.1.

— atmosphere coupling strength. J. Hydrometeor., 14, 16361646, https://doi.org/10.1175/JHM-D-12-0171.1.

Higgins, R. W., Y. Yao, E. S. Yaresh, J. E. Janowiak, and K. C. Mo, 1997: Influence of the Great Plains low-level jet on summertime precipitation and moisture transport over the central United States. J. Climate, 10, 481-507, https://doi.org/10.1175/ 1520-0442(1997)010<0481:IOTGPL > 2.0.CO;2.

Hohenegger, C., P. Brockhaus, C. S. Bretherton, and C. Schär, 2009: The soil moisture-precipitation feedback in simulations with explicit and parameterized convection. J. Climate, 22, 5003-5020, https://doi.org/10.1175/2009JCLI2604.1.

Hong, S.-Y., and E. Kalnay, 2000: Role of sea surface temperature and soil-moisture feedback in the 1998 Oklahoma-Texas drought. Nature, 408, 842-844, https://doi.org/10.1038/35048548.

Illston, B. G., J. B. Basara, and K. C. Crawford, 2004: Seasonal to interannual variations of soil moisture measured in Oklahoma. Int. J. Climatol., 24, 1883-1896, https://doi.org/ 10.1002/joc.1077.

$\longrightarrow,-$ D. K. Fisher, C. Fiebrich, K. Humes, R. Elliott, K. C. Crawford, and E. Hunt, 2008: Mesoscale monitoring of soil moisture across a statewide network. J. Atmos. Oceanic Technol., 25, 167-182, https://doi.org/10.1175/2007JTECHA993.1.

Koster, R. D., and Coauthors, 2004: Regions of strong coupling between soil moisture and precipitation. Science, 305, 11381140, https://doi.org/10.1126/science.1100217.

—-, and Coauthors, 2006: GLACE: The Global Land-Atmosphere Coupling Experiment. Part I: Overview. J. Hydrometeor., 7, 590-610, https://doi.org/10.1175/JHM510.1.

—_ and Coauthors, 2011: The second phase of the Global LandAtmosphere Coupling Experiment: Soil moisture contributions to subseasonal forecast skill. J. Hydrometeor., 12, 805-822, https://doi.org/10.1175/2011JHM1365.1.

, Y. Chang, H. Wang, and S. D. Schubert, 2016: Impacts of local soil moisture anomalies on the atmospheric circulation and on remote surface meteorological fields during boreal summer: A comprehensive analysis over North America.
J. Climate, 29, 7345-7364, https://doi.org/10.1175/JCLI-D-160192.1.

May, R. M., S. C. Arms, P. Marsh, E. Bruning, and J. R. Leeman, 2017: MetPy: A Python package for meteorological data. Unidata, accessed 31 March 2017, https://doi.org/10.5065/ D6WW7G29.

McKee, T. B., N. J. Doesken, and J. Kleist, 1993: The relationship of drought frequency and duration to time scales. Preprints, Eighth Conf. on Applied Climatology, Anaheim, CA, Amer. Meteor. Soc., 179-184.

McPherson, R. A., and Coauthors, 2007: Statewide monitoring of the mesoscale environment: A technical update on the Oklahoma Mesonet. J. Atmos. Oceanic Technol., 24, 301-321, https://doi.org/10.1175/JTECH1976.1.

Meng, L., and S. M. Quiring, 2010: Examining the influence of spring soil moisture anomalies on summer precipitation in the U.S. Great Plains using the Community Atmosphere Model version 3. J. Geophys. Res., 115, D21118, https://doi.org/10.1029/ 2010JD014449.

Mesinger, F., and Coauthors, 2006: North American Regional Reanalysis. Bull. Amer. Meteor. Soc., 87, 343-360, https:// doi.org/10.1175/BAMS-87-3-343.

Namias, J., X. Yuan, and D. E. Cayan, 1988: Persistence of North Pacific sea surface temperature and atmospheric flow patterns. J. Climate, 1, 682-703, https://doi.org/10.1175/1520-0442(1988) $001<0682:$ PONPSS $>2.0$.CO;2.

Pal, J. S., and E. A. B. Eltahir, 2003: A feedback mechanism between soil-moisture distribution and storm tracks. Quart. J. Roy. Meteor. Soc., 129, 2279-2297, https://doi.org/10.1256/ qj.01.201.

Phillips, T. J., and S. A. Klein, 2014: Land-atmosphere coupling manifested in warm-season observations on the U.S. southern Great Plains. J. Geophys. Res. Atmos., 119, 509-528, https:// doi.org/10.1002/2013JD020492.

Pielke, R. A., 2001: Influence of the spatial distribution of vegetation and soils on the prediction of cumulus convective rainfall. Rev. Geophys., 39, 151-177, https://doi.org/10.1029/ 1999RG000072.

Rabin, R. M., D. J. Stensrud, S. Stadler, P. J. Wetzel, and M. Gregory, 1990: Observed effects of landscape variability on convective clouds. Bull. Amer. Meteor. Soc., 71, 272-280, https://doi.org/10.1175/1520-0477(1990)071<0272:OEOLVO > 2.0.CO;2.

Raz-Yaseef, N., D. P. Billesbach, M. L. Fischer, S. C. Biraud, S. A. Gunter, J. A. Bradford, and M. S. Torn, 2015: Vulnerability of crops and native grasses to summer drying in the U.S. southern Great Plains. Agric. Ecosyst. Environ., 213, 209-218, https:// doi.org/10.1016/j.agee.2015.07.021.

Roundy, J. K., and J. A. Santanello, 2017: Utility of satellite remote sensing for land-atmosphere coupling and drought metrics. J. Hydrometeor., 18, 863-877, https://doi.org/10.1175/JHM-D16-0171.1.

_ C. R. Ferguson, and E. F. Wood, 2013: Temporal variability of land-atmosphere coupling and its implications for drought over the southeast United States. J. Hydrometeor., 14, 622635, https://doi.org/10.1175/JHM-D-12-090.1.

Santanello, J. A., C. D. Peters-Lidard, S. V. Kumar, C. Alonge, and W.-K. Tao, 2009: A modeling and observational framework for diagnosing local land-atmosphere coupling on diurnal time scales. J. Hydrometeor., 10, 577-599, https://doi.org/10.1175/ 2009JHM1066.1.

,-- , and — 2011: Diagnosing the sensitivity of local landatmosphere coupling via the soil moisture-boundary layer 
interaction. J. Hydrometeor., 12, 766-786, https://doi.org/10.1175/ JHM-D-10-05014.1.

$\longrightarrow,-$ A. Kennedy, and S. V. Kumar, 2013: Diagnosing the nature of land-atmosphere coupling: A case study of dry/wet extremes in the U.S. southern Great Plains. J. Hydrometeor., 14, 3-24, https://doi.org/10.1175/JHM-D-12-023.1.

Schneider, J. M., D. K. Fisher, R. L. Elliott, G. O. Brown, and C. P. Bahrmann, 2003: Spatiotemporal variations in soil water: First results from the ARM SGP CART network. J. Hydrometeor. 4, 106-120, https://doi.org/10.1175/1525-7541(2003)004<0106: SVISWF $>2.0 . \mathrm{CO} ; 2$.

Schubert, S. D., M. J. Suarez, P. J. Pegion, R. D. Koster, and J. T. Bacmeister, 2004: Causes of long-term drought in the U.S. Great Plains. J. Climate, 17, 485-503, https://doi.org/10.1175/ 1520-0442(2004)017<0485:COLDIT>2.0.CO;2.

Scott, B. L., T. E. Ochsner, B. G. Illston, C. A. Fiebrich, J. B. Basara, and A. J. Sutherland, 2013: New soil property database improves Oklahoma Mesonet soil moisture estimates. J. Atmos. Oceanic Technol., 30, 2585-2595, https://doi.org/ 10.1175/JTECH-D-13-00084.1.

Shapiro, A., E. Fedorovich, and S. Rahimi, 2016: A unified theory for the Great Plains nocturnal low-level jet. J. Atmos. Sci., 73, 3037-3057, https://doi.org/10.1175/JAS-D-15-0307.1.

Song, H.-J., C. R. Ferguson, and J. K. Roundy, 2016: Landatmosphere coupling at the Southern Great Plains Atmospheric Radiation Measurement (ARM) field site and its role in anomalous afternoon peak precipitation. J. Hydrometeor., 17, 541-556, https://doi.org/10.1175/JHM-D-15-0045.1.

Song, J., K. Liao, R. L. Coulter, and B. M. Lesht, 2005: Climatology of the low-level jet at the southern Great Plains atmospheric boundary layer experiments site. J. Appl. Meteor., 44, 15931606, https://doi.org/10.1175/JAM2294.1.

Stensrud, D. J., 1996: Importance of low-level jets to climate: A review. J. Climate, 9, 1698-1711, https://doi.org/10.1175/15200442(1996)009<1698:IOLLJT>2.0.CO;2.

Su, H., and R. E. Dickinson, 2017: On the Spatial gradient of soil moisture-precipitation feedback strength in the April 2011 drought in the southern Great Plains. J. Climate, 30, 829-848, https://doi.org/10.1175/JCLI-D-13-00185.1.

—, Z.-L. Yang, R. E. Dickinson, and J. Wei, 2014: Spring soil moisture-precipitation feedback in the southern Great Plains: How is it related to large-scale atmospheric conditions? Geophys. Res. Lett., 41, 1283-1289, https://doi.org/10.1002/2013GL058931.

Svoboda, M., and Coauthors, 2002: The Drought Monitor. Bull. Amer. Meteor. Soc., 83, 1181-1190, https://doi.org/10.1175/ 1520-0477-83.8.1181.

Tawfik, A. B., 2016: CoMeT: Coupling Metrics Toolkit. Coupling Metrics, accessed 13 November 2017, http://www.couplingmetrics.com.

Taylor C. M., and T. Lebel, 1998: Observational evidence of persistent convective-scale rainfall patterns. Mon. Wea. Rev., 126, 1597-1607, https://doi.org/10.1175/1520-0493(1998)126<1597: OEOPCS $>2.0 . \mathrm{CO} ; 2$.

Taylor, C. M., D. J. Parker, and P. P. Harris, 2007: An observational case study of mesoscale atmospheric circulations induced by soil moisture. Geophys. Res. Lett., 34, L15801, https://doi.org/ 10.1029/2007GL030572.

A. Gounou, F. Guichard, P. P. Harris, R. J. Ellis, F. Couvreux, and M. D. Kauwe, 2011: Frequency of Sahelian storm initiation enhanced over mesoscale soil-moisture patterns. Nat. Geosci., 4, 430-433, https://doi.org/10.1038/ ngeo1173.

, R. A. M. de Jeu, F. Guichard, P. P. Harris, and W. A. Dorigo, 2012: Afternoon rain more likely over drier soils. Nature, $\mathbf{4 8 9}$, 423-426, https://doi.org/10.1038/nature11377.

Teufel, B., and Coauthors, 2017: Investigation of the 2013 Alberta flood from weather and climate perspectives. Climate Dyn., 48, 2881-2899, https://doi.org/10.1007/s00382-016-3239-8.

Teuling, A. J., S. I. Seneviratne, C. Williams, and P. A. Troch, 2006: Observed timescales of evapotranspiration response to soil moisture. Geophys. Res. Lett., 33, L23403, https://doi.org/ 10.1029/2006GL028178.

Tindall, J. A., and J. R. Kunkel, 1999: Field water in soils. Unsaturated Zone Hydrology for Scientists and Engineers, Prentice-Hall, 379-406.

Trenberth, K. E., 1999: Atmospheric moisture recycling: Role of advection and local evaporation. J. Climate, 12, 1368-1381, https://doi.org/10.1175/1520-0442(1999)012<1368:AMRROA> 2.0.CO;2.

_ and C. J. Guillemot, 1996: Physical processes involved in the 1988 drought and 1993 floods in North America. J. Climate, 9, 1288-1298, https://doi.org/10.1175/1520-0442(1996)009<1288: PPIITD>2.0.CO;2.

Wallace, J. M., 1975: Diurnal variations in precipitation and thunderstorm frequency over the conterminous United States. Mon. Wea. Rev., 103, 406-419, https://doi.org/10.1175/15200493(1975)103<0406:DVIPAT > 2.0.CO;2.

Weaver, J. E., 1958: Summary and interpretation of underground development in natural grassland communities. Ecol. Monogr., Vol. 28, Ecological Society of America, 55-78, https://doi.org/ 10.2307/1942275.

Wei, J., and P. A. Dirmeyer, 2012: Dissecting soil moistureprecipitation coupling. Geophys. Res. Lett., 39, L15309, https:// doi.org/10.1029/2012GL052351.

— , H. Su, and Z.-L. Yang, 2016: Impact of moisture flux convergence and soil moisture on precipitation: A case study for the southern United States with implications for the globe. Climate Dyn., 46, 467-481, https://doi.org/10.1007/s00382-0152593-2.

Welty, J., and X. Zeng, 2018: Does soil moisture affect warm season precipitation over the southern Great Plains? Geophys. Res. Lett., 45, 7866-7873, https://doi.org/10.1029/ 2018 GL078598.

Wilks, D. S., 2011: Statistical Methods in the Atmospheric Sciences. 3rd ed. Elsevier, 676 pp.

Williams, I. N., Y. Lu, L. M. Kueppers, W. J. Riley, S. C. Biraud, J. E. Bagley, and M. S. Torn, 2016: Land-atmosphere coupling and climate prediction over the U.S. southern Great Plains. J. Geophys. Res. Atmos., 121, 12125-12144, https://doi.org/ 10.1002/2016JD025223. 